\title{
Spectra of a shallow sea-unmixing for class identification and monitoring of coastal waters
}

\author{
Annelies Hommersom • Marcel R. Wernand • \\ Steef Peters • Marieke A. Eleveld • \\ Hendrik Jan van der Woerd • Jacob de Boer
}

Received: 24 November 2009 / Accepted: 23 December 2010/Published online: 19 March 2011

(C) The Author(s) 2011. This article is published with open access at Springerlink.com

\begin{abstract}
Ocean colour-based monitoring of water masses is a promising alternative to monitoring concentrations in heterogeneous coastal seas. Fuzzy methods, such as spectral unmixing, are especially well suited for recognition of water masses from their remote sensing reflectances. However, such models have not yet been applied for water classification and monitoring. In this study, a fully constrained endmember model with simulated endmembers was developed for water class identification in the shallow Wadden Sea and adjacent German Bight. Its performance was examined on in situ measured reflectances and on MERIS satellite data. Water classification by means of unmixing reflectance spectra proved to be successful. When the endmember model was applied to MERIS data, it was able to visualise well-known spatial, tidal, seasonal, and wind-related variations in optical properties in the hetero-
\end{abstract}

Responsible Editor: Andreas Oschlies

A. Hommersom $(\bowtie) \cdot$ S. Peters $\cdot$ M. A. Eleveld

H. van der Woerd $\cdot$ J. de Boer

Institute for Environmental Studies (IVM), VU University,

De Boelelaan 1085,

1081 HV Amsterdam, the Netherlands

e-mail: annelies.hommersom@gmail.com

S. Peters

e-mail: steef.peters@ivm.vu.nl

M. A. Eleveld

e-mail: marieke.eleveld@ivm.vu.nl

H. van der Woerd

e-mail: hans.van.der.woerd@ivm.vu.nl

J. de Boer

e-mail: jacob.de.boer@ivm.vu.nl

M. R. Wernand

Royal Netherlands Institute for Sea Research (NIOZ),

P.O. Box 59, 1790 AB Den Burg (Texel), the Netherlands

e-mail: wernand@nioz.nl geneous Wadden Sea. Analyses show that the method is insensitive to small changes in endmembers. Therefore, it can be applied in similar coastal areas. For use in open ocean situations or coastal or inland waters with other specific inherent optical properties, re-simulation of the endmember spectra with local optical properties is required. However, such an adaptation requires only a limited number of local in situ measurements.

Keywords Endmember $\cdot$ Reflectance $\cdot$ MERIS $\cdot$ Water mass $\cdot$ Unmixing

\section{Introduction}

Coastal waters are often very heterogeneous in composition due to river discharge, land runoff, oceanic influence, and human activities. Due to high concentrations of sediment in these waters, precise retrieval of concentrations of chlorophyll $a(\mathrm{Chl} a)$, suspended particulate matter (SPM) and coloured dissolved organic matter (CDOM) from remote sensing data can be problematic. As an alternative for retrieval and monitoring based on concentrations, this study presents a simple method for the mapping of water masses.

Tomczak (1999) defines a water mass as: 'a body of water with a common formation history, having its origin in a particular region of the ocean'. This water mass formation 'can be seasonal or intermittent in time' (Tomczak 1999). When monitoring water masses it is important to consider that some properties, such as salinity, are conservative. These properties are stable in time and changes of their values can only be attributed to mixing (Tomczak 1999). Non-conservative properties change over time due to, for example, biodegradation, resuspension or settling. In papers on optical water mass monitoring (e.g. Oliver and Irwin 2008; Van der Woerd et al. 2004), the definition of a water 
mass differs depending on the method used. The main difference in definitions can be found in the handling of non-conservative properties.

In this study, waters with similar colours (read: 'similar reflectance spectra'), expressed by similar total absorption and scattering properties (the inherent optical properties or IOPs) are assigned to the same water 'class'. In these waters, the specific inherent optical properties (SIOPs) might still be different and therefore also the concentrations of Chl $a$, SPM and CDOM do not have to be similar within one water class. In this study, waters with similar SIOPs are assigned the same water 'type', even when the present concentrations (and thereby reflectances) change.

Both water classes and water types can show large variability in time and space (e.g. Blondeau-Patissier et al. 2004; Doxaran et al. 2005, 2006) and have been used successfully for water mass identification. Water types were identified with an inverse bio-optical model called HYDROPT by Van der Woerd et al. (2004). Inverse biooptical models were also used to define water classes, as in Hoge and Lyon (2005) and Schofield et al. (2004). However, for water classification, clustering is a more general technique. Various components, such as $\mathrm{Chl} a$ concentration, reflectances and Secchi depths can be used as clustering properties (e.g. Reinart et al. 2003). Clustering based on reflectance spectra, combined with salinity or temperature, has led to good classification results in various oceanic areas. For example Oliver and Irwin (2008) were able to monitor the effect of El Niño events, and Lubac and Loisel (2007) could determine the presence of Phaeocystis globosa based on spectral shapes. Improvements of the clustering technique were studied by Oliver et al. (2004). Combining two theories, Feng et al. (2005) created a clustering technique to determine three water classes. In the next step, they assumed the water types in these water classes to be different. Then, they derived concentrations with three separately calibrated biooptical models. Indeed, their retrieval of concentrations improved compared with the original bio-optical model. A more sophisticated version of this method was already proposed earlier by Moore et al. (2001), who used unconstrained unmixing to determine water classes and subsequently derive concentrations with algorithms calibrated for the various water classes. This suggests that water types (SIOPs) can vary with water classes (based on IOPs).

Another important point on water mass identification is the distinction between hard classification, in which a pixel is classified as belonging to one or another water mass, and fuzzy classifications, in which boundaries are gradual and pixels can be classified as a mixture of water masses. Water is subject to local mixing and non-conservative properties gradually disappear or reappear in water masses. Therefore, fuzzy methods are better suited for water mass monitoring (Moore et al. 2009). Most classifications based on clustering and inverse bio-optical models give hard classifications. Only Oliver et al. (2004) pay attention to the boundaries between clusters in their model.

Endmember models definition by lead to fuzzy classifications. These models are based on spectral shapes: the model unmixes a given pixel in percentages, or abundances, of given endmembers and are therefore also referred to as unmixing techniques. Unmixing is widely used in land remote sensing (e.g. Zurita-Milla 2008, Asner and Heidebrecht 2002) and for tidal flat identification (e.g. Doerffer and Murphy 1989). However, only a few studies are available that applies unmixing to water reflectances (Moore et al. 2001; Tyler et al. 2005; Jianguang et al. 2007; Moore et al. 2009). Moore et al. (2001) base their approach on the fuzzy property of endmember models to blend algorithms and retrieve concentration maps without discontinuities. This approach still requires algorithms to be calibrated with the appropriate local SIOPs for monitoring concentrations. To avoid this problem, our approach is to monitor (IOP based) water 'classes' instead of (SIOP based) water 'types' and related concentrations. This requires a fully constrained endmember model, as the total of water masses should be positive and sum to $100 \%$. Only Jianguang et al. (2007) and Moore et al. (2009) have successfully applied this type of model to reflectances of water. Jianguang et al. (2007) normalised or differentiated the spectrum before unmixing and used the derived abundances to calculate the concentration of $\mathrm{Chl} a$. However, due to spectral calculations the model loses its sensitivity to monitor water classes influenced by SPM. Moore et al. (2009) presented promising primarily global results. Studies in which an endmember model is used for monitoring (e.g. comparing images of various days) of water classes are not known to the authors.

The objective of this study was to develop an endmember model for water classification and to examine its ability for monitoring water classes in the heterogeneous Wadden Sea based on MEdium Resolution Imaging Spectrometer (MERIS) satellite data. Monitoring requires an objective and standardised technique, which allows comparison of data of one place or moment to that of next day, or to that of another situation.

\section{Material and methods}

\subsection{In situ and MERIS data}

Reflectance spectra from in situ measurements and from MERIS data were used as model input. In situ remote sensing reflectance (Rrs) was derived from two radiance and one irradiance sensors (TriOS, RAMSES (Heuermann et al. 1999)), according to the Ocean Optics protocols (Mueller et al. 2003). Measurements were carried out in March, May, June, July, August and September 2006 (120 
stations) and in May 2007 (37 stations) (Hommersom et al. 2009). At four stations negative reflectance was calculated at the blue bands and four stations the reflectance varied much over the series of measurements. The remaining 132 reflectance spectra were sub-sampled at MERIS bands and used as model input. Simultaneously with the reflectance measurements, water samples were obtained to determine the concentrations of Chl $a$, SPM, and the absorption by CDOM, of which the sampling and analysis details can be found in Hommersom et al. (2009).

Meteorological data at the day of data acquisition (wind speed and wind direction at the weather station at Lauwersoog $\left.\left(53.24^{\circ} \mathrm{N}, 6.2^{\circ} \mathrm{E}\right)\right)$ were extracted from the Royal Netherlands Meteorological Institute's database (www.knmi.nl/klimatologie/daggegevens/download.html).

MERIS full resolution (FR) data were obtained and processed to reflectance at sea level with the 'Improved Contrast between Ocean and Land' (ICOL) (Santer and Zagolski 2009) and the Case-2 Regional processor (C2R) (Doerffer and Schiller 2006a, 2006b). MERIS images with low cloud cover over the Wadden Sea were selected from the years 2006 and 2007. Specific information on MERIS data are given in Appendix 1.

\subsection{Endmember model}

An endmember model was created to determine the subpixel percentages coverage (abundance) of water classes. The model is formulated as Eq. 1. The observed (TriOS or MERIS) reflectances (Rrs) are used as input. $R_{1}$ to $R_{n}$ are the pre-defined endmember spectra, the spectral shapes of the water classes. Coefficients $c_{1}-c_{n}$ are the abundances that will be determined in the unmixing process. Rrs and $R_{1}-R_{n}$ are a function of wavelength $(\lambda)$, but $\lambda$ was excluded in the equations for readability.

$$
\begin{aligned}
\operatorname{Rrs}_{\text {measured }} & =c_{1} R_{1}+c_{2} R_{2}+c_{3} R_{3}+\ldots c_{n} R_{n \mathrm{~b}}+\text { error } \\
& =\operatorname{Rrs}_{\text {modelled }}+\text { error }
\end{aligned}
$$

In order to come to a realistic solution, it is necessary to use a fully constrained method, in which the abundances are non-negative (Eq. 2) and the sum of the abundances is one (Eq. 3).

$c_{1} \geq 0, c_{2} \geq 0, c_{3} \geq 0, \ldots, c_{n} \geq 0$

$c_{1}+c_{2}+c_{3}+\ldots,+c_{n}=1$

Thus, the model reflects the physical interpretation that a pixel should contain at least one water class and abundances sum to $100 \%$ (Appendix 2).

The spectral fit between the measured and the modelled spectrum is calculated as the root mean squared error (RMSE), according to Eq. 4. The RMSE is calculated as the difference between the modelled and the measured reflectance spectrum over the nine $(m=1-9)$ MERIS wavelength bands. The RMSE was used to flag pixels for which the unmixing process failed (arbitrarily set to $\mathrm{RMSE} \geq 0.01$ ).

$\mathrm{RMSE}=\sqrt{\sum_{m=1}^{m=9} \frac{\left[\operatorname{Rrs} \text { measured }-\left(c_{1} R_{1}+c_{2} R_{2}+c_{3} R_{3}+\ldots c_{n} R_{n}\right)\right]^{2}}{n}}$

\subsection{Endmember generation}

There are several strategies towards endmember identification (Appendix 3). One strategy would be to collect endmember spectra from the dataset of observations (either in situ or satellite images). However, not all extremes in water classes were captured during the in situ campaigns, while selecting endmembers from MERIS data (representing the extremes for the whole Wadden Sea area over all seasons) would require extensive data-processing or non-objective selection. Therefore, endmembers were simulated based on prior knowledge of the optical properties in the Wadden Sea (Hommersom et al., 2009). The endmember spectra were simulated with the Gordon (Gordon et al. 1975; Jerlov 1976) model (Eq. 5) in combination with equations relating the IOPs to SIOPs and the concentrations of SPM ([SPM]), Chl
Table 1 Concentrations used in the Gordon model to generate the endmembers

\begin{tabular}{llll}
\hline Endmember & {$[\mathrm{Chl}]$} & {$[\mathrm{SPM}]$} & $a_{\text {CDOM }}(440)$ \\
\hline Pure water & 0 & 0 & 0 \\
Low-concentrations & 1 & 1 & 0.2 \\
CDOM-dominated & 1 & 1 & 3 \\
CDOM-Chl-dominated & 60 & 1 & 3 \\
Chl-dominated & 60 & 1 & 0.2 \\
SPM-dominated & 1 & 100 & 0.2 \\
SPM-CDOM-dominated & 1 & 100 & 3 \\
SPM-Chl-dominated & 60 & 100 & 0.2 \\
High concentrations & 60 & 100 & 3 \\
\hline
\end{tabular}



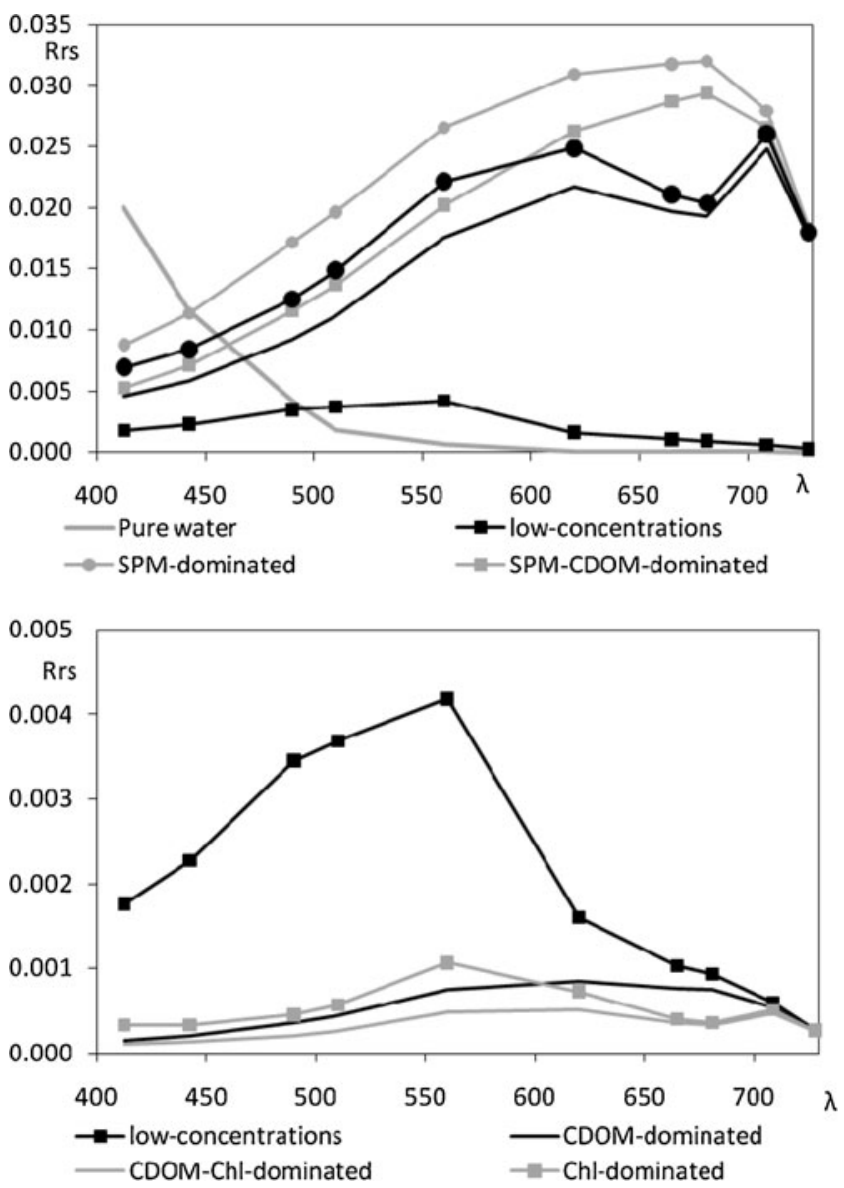

Fig. 1 Endmembers. Note the scale difference between a and $\mathbf{b}$. The low-concentration endmember is shown in both graphs for comparison
([Chl]) and the absorption of CDOM at $440 \mathrm{~nm}$ (aCDOM). Some background on endmember selection is given in Appendix 2; the Gordon model and equations are explained in Appendix 3.

Endmembers were generated for pure water, for water with low (SPM $1 \mathrm{gm}^{3}$, Chl $a 1 \mathrm{mg} \mathrm{m}^{3}$, CDOM $0.2 \mathrm{~m}^{-1}$ ) and high

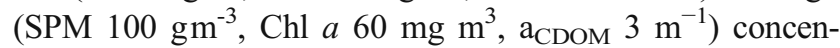
trations, and permutations of low and high concentrations for the three substances (so one substance with a low and two with a high concentration, or two with a low and one with a high concentration), leading to a total of nine endmembers (Table 1; Fig. 1) for nine wavelengths that correspond to the MERIS visual spectral bands. Therefore, in Eq. 4, $n=4$. Note that endmembers were not generated at the maximum [Chl $a$ ], [SPM] and $a_{\mathrm{CDOM}}$ occurring in the Wadden Sea, because extreme high concentrations would deform the spectrum. Meanwhile, creating endmembers based on ' $100 \%$ concentrations' is not possible for solutions in water.

\subsection{Testing the endmember model}

After generation of the endmembers their performance was examined. Firstly, the model was run with in situ measured reflectance spectra as input; subsequently the model was applied to MERIS data. The performance of the endmember model with MERIS data as input was evaluated by examining its abilities to visualise well-known spatial, seasonal, tidal and weather related variations of optical properties) in the Wadden Sea.

The endmember model was evaluated, first by comparing the spectral shape of the endmembers with in situ measured reflectance spectra. Next, the in situ measured reflectance data were unmixed and the derived abundances were compared
Fig. 2 In situ reflectances (Rrs), determined with TriOS sensors during several in situ campaigns on the Wadden Sea (Hommersom et al., 2009) (black lines). The grey shading is the coverage of the endmember model, determined by the minimum and maximum reflectances of the endmembers

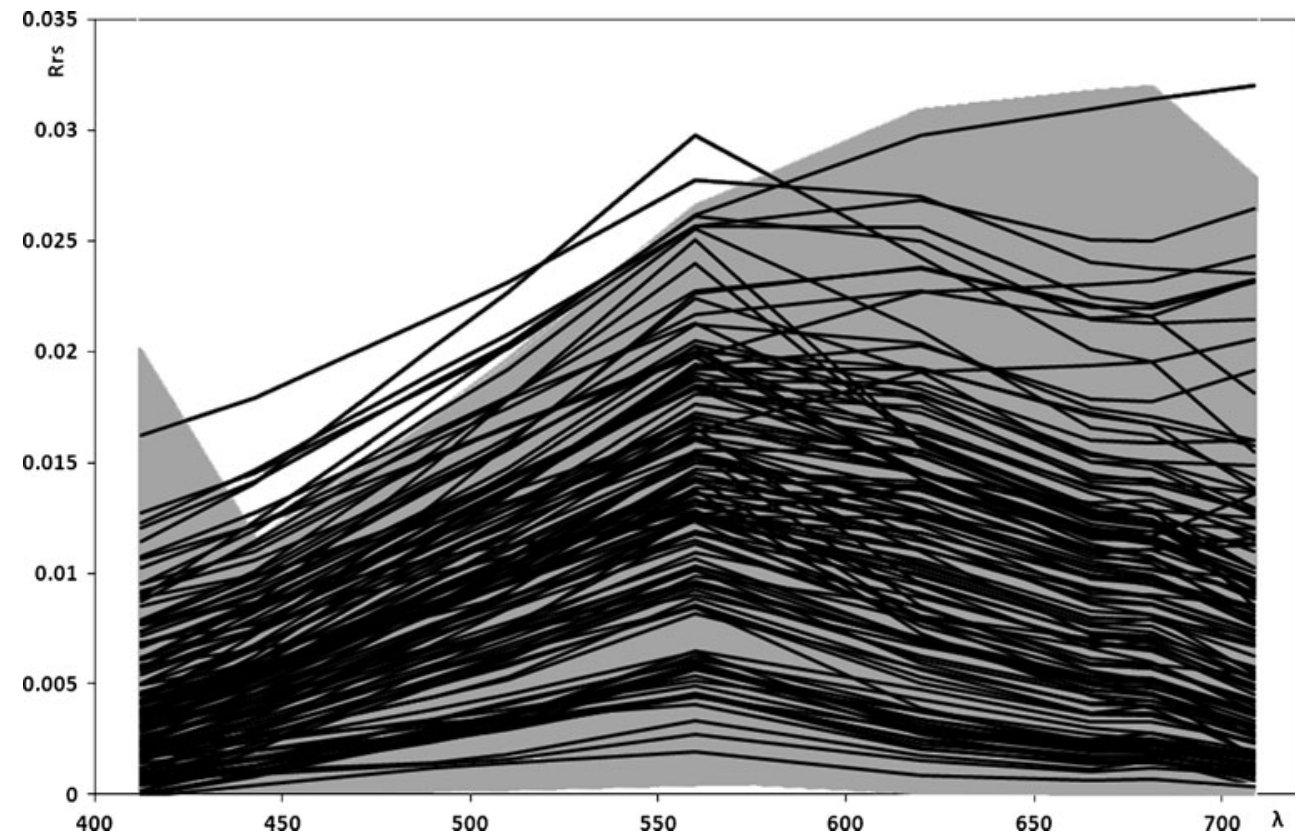


with the simultaneously measured concentrations of Chl $a$, SPM and CDOM. Finally, various MERIS images were used as model input and the ability of the model to visualise wellknown spatial, seasonal, tidal and weather related patterns in the Wadden Sea and adjacent North Sea was assessed. RMSE values were plotted for each unmixed MERIS image.

The overpass of MERIS is - at these latitudes - about twice every three days and are therefore very suitable for monitoring (e.g. Van der Wal et al., 2010). For summer, with clear weather conditions, two or three images of the whole area are available per week. In winter, with bad weather conditions, images usually contain (spotted) clouds, so that subsequent acquisition for one specific location might take some weeks to occur. However, spatial, seasonal and weather related variability become easily visible. Analyses of variations over the tidal cycle is more difficult, as each MERIS pass takes place at approximately the same time (10 am UTC). Visualisation of effects of tidal

Table 2 Results of unmixing in situ measured reflectance data

\begin{tabular}{|c|c|c|c|c|c|c|c|c|c|c|c|c|c|c|c|c|}
\hline \multirow[t]{2}{*}{ Date } & \multirow[t]{2}{*}{ Time } & \multirow{2}{*}{$\begin{array}{l}\text { GPS N } \\
\text { decimals }\end{array}$} & \multirow{2}{*}{$\begin{array}{l}\text { GPS E } \\
\text { decimals }\end{array}$} & \multicolumn{3}{|c|}{ In situ data } & \multicolumn{9}{|c|}{ Endmember abundances } & \multirow[t]{2}{*}{ RMSE } \\
\hline & & & & $\begin{array}{l}\text { Chl-a } \\
(\mathrm{mg} \\
\left.\mathrm{m}^{-3}\right)\end{array}$ & $\begin{array}{l}\text { SPM } \\
\left(\mathrm{g} \mathrm{m}^{-3}\right)\end{array}$ & $\begin{array}{l}\text { CDOM } \\
\left(\mathrm{m}^{-1}\right)\end{array}$ & 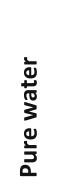 & $\begin{array}{l}\text { c் } \\
\text { ż } \\
\text { o }\end{array}$ & ¿ั & 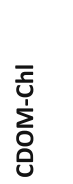 & 던 & $\sum_{0}$ & $\begin{array}{l}\sum_{0} \\
0 \\
\substack{1 \\
\vdots} \\
\dot{1}\end{array}$ & $\begin{array}{l}\bar{c} \\
\sum_{0}^{1} \\
\bar{n}\end{array}$ & 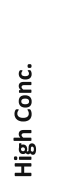 & \\
\hline 7-Mar-06 & $14: 20$ & 52.9882 & 4.7880 & 4.0 & 12.3 & n.a & 0.07 & 0.66 & 0.00 & 0.00 & 0.00 & 0.28 & 0.00 & 0.00 & 0.00 & $3.97 \mathrm{E}-03$ \\
\hline 9-Mar-06 & $17: 05$ & 53.0010 & 4.7868 & 7.2 & 13.1 & n.a & 0.05 & 0.72 & 0.00 & 0.00 & 0.00 & 0.24 & 0.00 & 0.00 & 0.00 & $3.59 \mathrm{E}-03$ \\
\hline 2-May-06 & $9: 36$ & 53.3015 & 5.2652 & 6.2 & 6.0 & 0.8 & 0.00 & 0.75 & 0.00 & 0.00 & 0.21 & 0.03 & 0.00 & 0.01 & 0.00 & $2.69 \mathrm{E}-04$ \\
\hline 2-May-06 & $16: 25$ & 53.4232 & 5.7993 & 15.7 & 62.4 & 1.0 & 0.28 & 0.08 & 0.00 & 0.00 & 0.00 & 0.51 & 0.00 & 0.13 & 0.00 & $2.40 \mathrm{E}-03$ \\
\hline 3-May-06 & $10: 36$ & 53.4468 & 6.1698 & 10.5 & 25.9 & 0.9 & 0.00 & 0.62 & 0.00 & 0.00 & 0.00 & 0.22 & 0.00 & 0.15 & 0.00 & $9.42 \mathrm{E}-04$ \\
\hline 3-May-06 & $15: 42$ & 53.4833 & 6.4708 & 6.3 & 7.5 & 1.0 & 0.00 & 0.68 & 0.00 & 0.00 & 0.25 & 0.07 & 0.00 & 0.00 & 0.00 & $7.48 \mathrm{E}-04$ \\
\hline 4-May-06 & $10: 14$ & 53.3818 & 6.9580 & 9.5 & 30.3 & 1.8 & 0.00 & 0.44 & 0.00 & 0.00 & 0.00 & 0.52 & 0.00 & 0.04 & 0.00 & $1.41 \mathrm{E}-03$ \\
\hline 5-May-06 & $8: 40$ & 53.5268 & 6.7540 & 12.6 & 6.7 & 1.1 & 0.00 & 0.45 & 0.00 & 0.00 & 0.44 & 0.00 & 0.05 & 0.06 & 0.00 & $1.02 \mathrm{E}-03$ \\
\hline 5-May-06 & $16: 34$ & 53.7885 & 7.5155 & 2.0 & 2.6 & 0.6 & 0.04 & 0.81 & 0.13 & 0.00 & 0.00 & 0.02 & 0.00 & 0.00 & 0.00 & 5.87E-05 \\
\hline 6-May-06 & $10: 51$ & 54.0528 & 8.2733 & 10.5 & 2.1 & 0.5 & 0.00 & 0.62 & 0.00 & 0.00 & 0.34 & 0.00 & 0.02 & 0.02 & 0.00 & 4.53E-04 \\
\hline 7-May-06 & $10: 19$ & 54.8610 & 8.2167 & 15.7 & 2.4 & 0.6 & 0.00 & 0.28 & 0.00 & 0.00 & 0.70 & 0.00 & 0.02 & 0.00 & 0.00 & 1.69E-04 \\
\hline 8-May-06 & $6: 27$ & 55.0950 & 8.3375 & 4.3 & 2.5 & 0.2 & 0.00 & 0.51 & 0.00 & 0.00 & 0.49 & 0.00 & 0.00 & 0.00 & 0.00 & $9.18 \mathrm{E}-04$ \\
\hline 9-May-06 & $6: 02$ & 54.5912 & 8.4035 & 6.6 & 7.2 & 0.9 & 0.00 & 0.89 & 0.00 & 0.00 & 0.00 & 0.07 & 0.00 & 0.03 & 0.00 & $1.09 \mathrm{E}-03$ \\
\hline 9-May-06 & $12: 08$ & 54.1417 & 8.7235 & 41.2 & 23.2 & 0.8 & 0.00 & 0.53 & 0.00 & 0.00 & 0.00 & 0.11 & 0.00 & 0.36 & 0.00 & $8.23 E-04$ \\
\hline 13-Jun-'06 & $10: 57$ & 53.0010 & 4.7870 & n.a & 30.0 & 0.9 & 0.00 & 0.70 & 0.00 & 0.00 & 0.00 & 0.28 & 0.00 & 0.03 & 0.00 & $1.08 \mathrm{E}-03$ \\
\hline 14-Jun-'06 & $7: 55$ & 53.0010 & 4.7870 & n.a & 22.0 & 0.7 & 0.00 & 0.60 & 0.00 & 0.00 & 0.00 & 0.33 & 0.00 & 0.06 & 0.00 & $1.22 \mathrm{E}-03$ \\
\hline 15-Jun-'06 & $11: 05$ & 53.0010 & 4.7870 & n.a & 24.0 & 0.5 & 0.00 & 0.79 & 0.00 & 0.00 & 0.00 & 0.19 & 0.00 & 0.01 & 0.00 & $1.34 \mathrm{E}-03$ \\
\hline 15-Jul-'06 & $10: 45$ & 53.0010 & 4.7870 & n.a & 25.2 & 0.7 & 0.00 & 0.70 & 0.00 & 0.00 & 0.00 & 0.12 & 0.00 & 0.18 & 0.00 & $8.25 E-04$ \\
\hline 15-Jul-'06 & $17: 45$ & 53.0010 & 4.7870 & n.a & 52.4 & 0.4 & 0.00 & 0.65 & 0.00 & 0.00 & 0.00 & 0.26 & 0.00 & 0.09 & 0.00 & $9.99 \mathrm{E}-04$ \\
\hline 19-Jul-'06 & $8: 10$ & 53.0010 & 4.7870 & n.a & 4.4 & 0.5 & 0.00 & 0.75 & 0.00 & 0.00 & 0.00 & 0.23 & 0.00 & 0.02 & 0.00 & $1.47 \mathrm{E}-03$ \\
\hline 21-Aug-'06 & $13: 00$ & 53.2360 & 5.2585 & 25.4 & 20.8 & 0.5 & 0.10 & 0.33 & 0.00 & 0.00 & 0.00 & 0.37 & 0.00 & 0.20 & 0.00 & $2.54 \mathrm{E}-03$ \\
\hline 22-Aug-'06 & $10: 50$ & 53.4968 & 6.0128 & 12.1 & 63.6 & 0.5 & 0.00 & 0.46 & 0.00 & 0.00 & 0.00 & 0.40 & 0.00 & 0.14 & 0.00 & $1.93 \mathrm{E}-03$ \\
\hline 23-Aug-'06 & $10: 25$ & 53.4963 & 6.4028 & 5.1 & 16.8 & 0.3 & 0.15 & 0.41 & 0.00 & 0.00 & 0.00 & 0.44 & 0.00 & 0.00 & 0.00 & $3.96 \mathrm{E}-03$ \\
\hline 23-Aug-'06 & $18: 00$ & 53.4960 & 6.4023 & 13.2 & 38.4 & 0.7 & 0.00 & 0.52 & 0.00 & 0.00 & 0.00 & 0.34 & 0.00 & 0.14 & 0.00 & $1.77 \mathrm{E}-03$ \\
\hline 25-Aug-'06 & $4: 55$ & 53.4963 & 6.4032 & 7.8 & 20.8 & 0.8 & 0.01 & 0.71 & 0.00 & 0.00 & 0.00 & 0.24 & 0.00 & 0.05 & 0.00 & $1.55 \mathrm{E}-03$ \\
\hline 26-Aug-'06 & $17: 05$ & 53.4963 & 6.4032 & 14.6 & 19.6 & 0.8 & 0.00 & 0.71 & 0.00 & 0.00 & 0.00 & 0.16 & 0.00 & 0.13 & 0.00 & $1.27 \mathrm{E}-03$ \\
\hline 29-Aug-'06 & $10: 37$ & 53.4172 & 6.2135 & 20.8 & 65.2 & 0.7 & 0.00 & 0.56 & 0.00 & 0.00 & 0.00 & 0.25 & 0.00 & 0.19 & 0.00 & $6.08 \mathrm{E}-04$ \\
\hline 30-Aug-'06 & $10: 05$ & 53.4262 & 6.0572 & 24.7 & 46.4 & 0.6 & 0.10 & 0.23 & 0.00 & 0.00 & 0.00 & 0.47 & 0.00 & 0.20 & 0.00 & $2.19 \mathrm{E}-03$ \\
\hline 31-Aug-'06 & $7: 45$ & 53.2337 & 5.2943 & 22.3 & 15.6 & 0.6 & 0.00 & 0.71 & 0.00 & 0.00 & 0.00 & 0.19 & 0.00 & 0.10 & 0.00 & $2.52 \mathrm{E}-03$ \\
\hline 18-Sep-'06 & $10: 08$ & 53.0945 & 5.0645 & 8.4 & 5.4 & 0.9 & 0.00 & 0.84 & 0.00 & 0.00 & 0.13 & 0.00 & 0.02 & 0.01 & 0.00 & 8.63E-04 \\
\hline 18-Sep-'06 & $16: 30$ & 53.3967 & 5.5738 & 4.7 & 3.2 & n.a & 0.18 & 0.56 & 0.00 & 0.00 & 0.00 & 0.26 & 0.00 & 0.00 & 0.00 & 2.19E-03 \\
\hline 20-Sep-'06 & $14: 45$ & 53.4957 & 6.4020 & 15.8 & 25.6 & 0.5 & 0.02 & 0.68 & 0.00 & 0.00 & 0.00 & 0.23 & 0.00 & 0.06 & 0.00 & $1.33 \mathrm{E}-03$ \\
\hline 21-Sep-'06 & $8: 15$ & 53.4953 & 6.4013 & 8.6 & 13.2 & n.a & 0.01 & 0.75 & 0.00 & 0.00 & 0.00 & 0.23 & 0.00 & 0.00 & 0.00 & $1.68 \mathrm{E}-03$ \\
\hline 21-Sep-'06 & $11: 15$ & 53.4957 & 6.4022 & 11.8 & 53.6 & 0.7 & 0.00 & 0.65 & 0.00 & 0.00 & 0.00 & 0.33 & 0.00 & 0.03 & 0.00 & $1.75 \mathrm{E}-03$ \\
\hline 21-Sep-'06 & $14: 15$ & 53.4957 & 6.4020 & 4.0 & 27.6 & 0.6 & 0.00 & 0.65 & 0.00 & 0.00 & 0.00 & 0.29 & 0.00 & 0.06 & 0.00 & $1.47 \mathrm{E}-03$ \\
\hline 7-May-'07 & $10: 55$ & 53.2215 & 4.9523 & 14.0 & 3.6 & 0.7 & 0.00 & 0.69 & 0.00 & 0.00 & 0.25 & 0.03 & 0.01 & 0.01 & 0.00 & 5.59E-04 \\
\hline 8-May-'07 & $8: 25$ & 53.1600 & 5.1993 & 11.0 & 41.2 & 0.7 & 0.09 & 0.44 & 0.00 & 0.00 & 0.00 & 0.43 & 0.00 & 0.03 & 0.00 & $2.54 \mathrm{E}-03$ \\
\hline 8-May-'07 & $11: 27$ & 53.3067 & 5.4045 & 10.4 & 32.0 & 0.9 & 0.05 & 0.46 & 0.00 & 0.00 & 0.00 & 0.46 & 0.00 & 0.03 & 0.00 & $2.23 \mathrm{E}-03$ \\
\hline 9-May-'07 & $9: 45$ & 53.3088 & 5.5455 & 64.5 & 452.0 & n.a & 0.17 & 0.00 & 0.00 & 0.00 & 0.00 & 0.50 & 0.00 & 0.34 & 0.00 & $1.50 \mathrm{E}-03$ \\
\hline 11-May-'07 & $13: 40$ & 53.3152 & 7.1600 & 32.0 & 290.0 & 1.5 & 0.00 & 0.21 & 0.00 & 0.00 & 0.00 & 0.05 & 0.35 & 0.00 & 0.40 & 5.39E-04 \\
\hline 11-May-'07 & $17: 20$ & 53.3878 & 6.9672 & 27.2 & 14.4 & 1.5 & 0.04 & 0.39 & 0.00 & 0.00 & 0.00 & 0.31 & 0.00 & 0.26 & 0.00 & $1.43 \mathrm{E}-03$ \\
\hline 13-May-'07 & $9: 25$ & 53.9133 & 8.0730 & 24.9 & 9.2 & 0.6 & 0.00 & 0.33 & 0.00 & 0.00 & 0.65 & 0.02 & 0.00 & 0.00 & 0.00 & $3.05 E-04$ \\
\hline 14-May-'07 & $10: 30$ & 54.1092 & 8.8662 & 38.5 & 30.0 & 0.7 & 0.06 & 0.42 & 0.00 & 0.00 & 0.00 & 0.26 & 0.00 & 0.26 & 0.00 & $1.21 \mathrm{E}-03$ \\
\hline 14-May-'07 & $14: 15$ & 54.1133 & 8.8663 & $>60$ & 154.0 & 0.5 & 0.00 & 0.10 & 0.33 & 0.00 & 0.00 & 0.00 & 0.04 & 0.00 & 0.54 & $1.29 \mathrm{E}-03$ \\
\hline
\end{tabular}

The table presents in situ concentrations and derived endmember abundances. Due to space restraints, not all the data of the 132 spectra were presented. Data were listed in order of sampling time and data of every 3rd station is presented. Grey shading for abundances $>0$, dark grey shading for abundances $>0.25$ 
changes on water classes requires MERIS images acquired at various moments in the tidal cycle and therefore images of several weeks, obtained under similar conditions.

To analyse the vulnerability of the endmember model to small changes in endmembers, we re-generated the endmembers based on $10 \%$ higher concentrations of each substance (Eqs. 6 and 7), for the low concentrations as well as for the high concentrations. With this alternative set of endmembers, the model was run again on the in situ obtained TriOS refectances. The resulting abundances were compared with the abundances as derived with the original endmember set.

\section{Results and discussion}

\subsection{Validation of the endmembers and the model}

The coverage of the endmember model, relative to the in situ measured reflectances is shown in Fig. 2. The reflectances of the simulated endmembers with the lowest values were lower than any of the measured spectra, while the reflectances of the endmembers with the highest values were higher than almost all in situ measured spectra (Fig. 2), indicating suitable endmembers for this area. However, the endmembers with the highest reflectances have a somewhat different reflectance in the last band $(708 \mathrm{~nm})$ than the in situ spectra with the highest reflectances. This could be due to other SIOPs for SPM at these in situ stations than the median

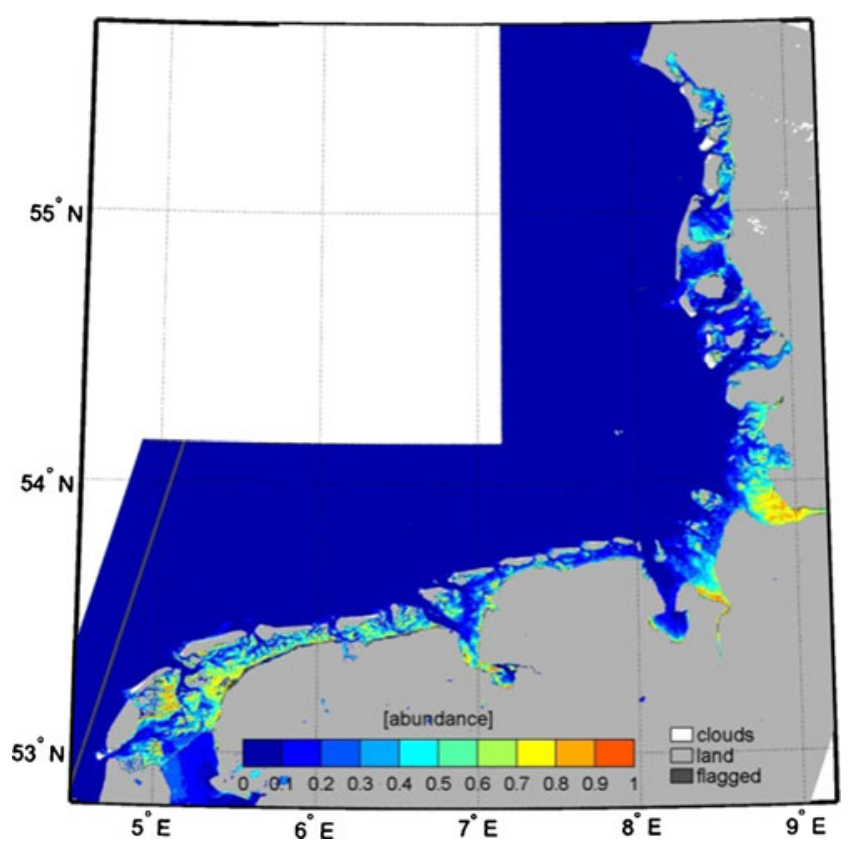

Fig. 3 Abundance of the SPM-Chl-dominated endmember with calm weather, illustrated with the image of May 10th 2006 when the daily average wind speed was $4.7 \mathrm{~ms}^{-1}$ and the highest hourly average wind, speed $6.0 \mathrm{~ms}^{-1}$. The flagged line in the west is an error caused by the first version of the ICOL processor
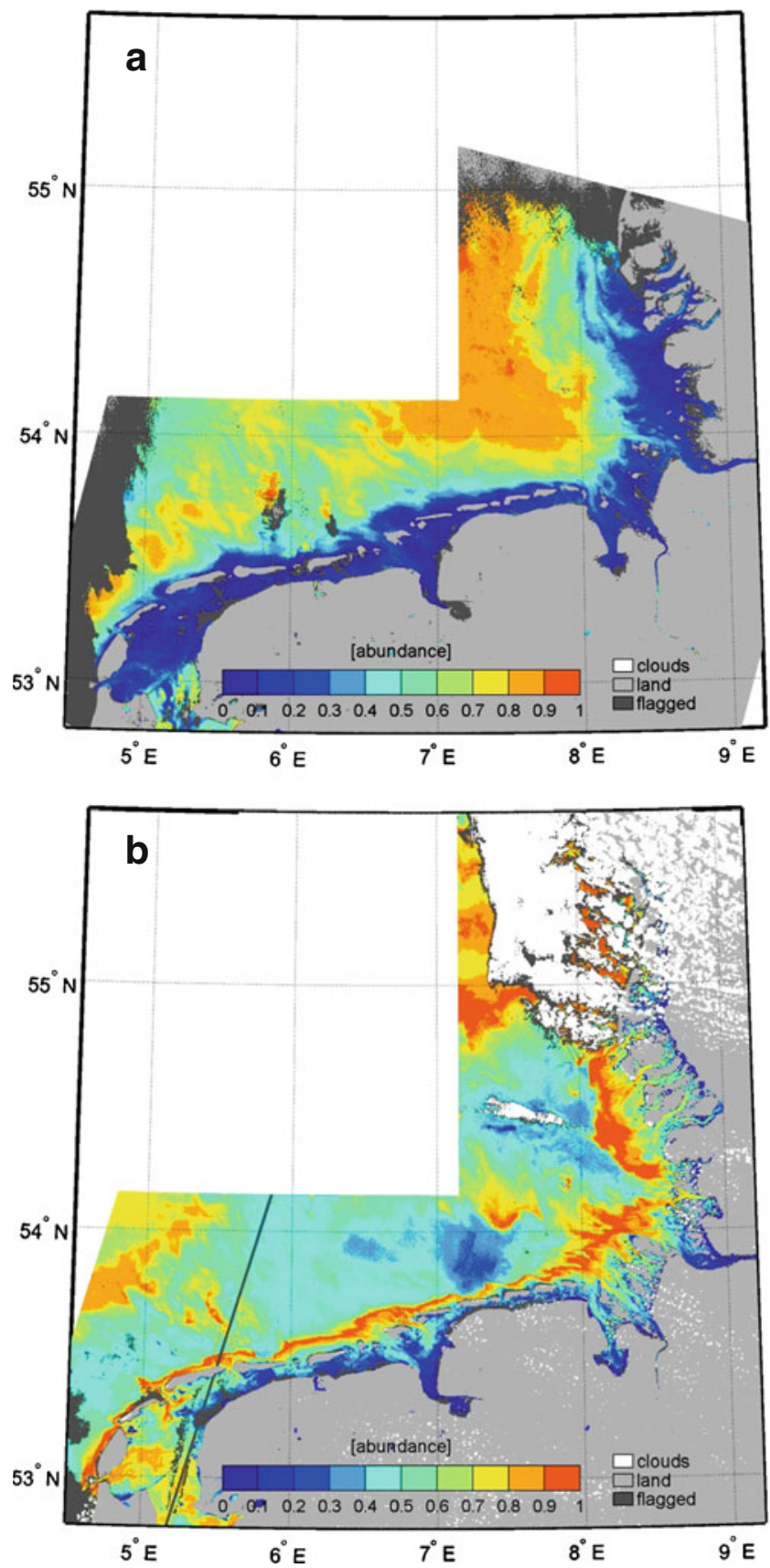

Fig. 4 Abundance of the low-concentrations endmember at days with comparable wind speeds: $\mathbf{a}$ in winter, illustrated with the image of January 16th 2006 (daily average south-easterly wind $6.8 \mathrm{~ms}^{-1}$, highest hourly average wind $8.0 \mathrm{~ms}^{-1}$ ), which could not be processed with the ICOL processor; $\mathbf{b}$ in summer, illustrated with the image of June 30th 2006 (daily average north easterly wind $6.1 \mathrm{~ms}^{-1}$, highest hourly average wind $9.0 \mathrm{~ms}^{-1}$ ). The flagged line is an error caused by the first version of the ICOL processor

value that was used to generate the endmembers. The discrepancies are not too large: such a spectrum will still be unmixed with the most suitable endmembers and the abundance results will be minimally influenced. The high coverage of the endmembers at $412 \mathrm{~nm}$ is due to the pure- 
water endmember. Although spectra with very low concentrations (and therefore high reflectance in the blue wavelengths) were missing in our in situ set, such an endmember was necessary to unmix spectra at locations with very low concentrations in the German Bight.

Abundances derived from unmixing in situ measured spectra were compared with the in situ data of [Chl], [SPM] and $a_{\mathrm{CDOM}}$ in Table 2. Abundances of endmembers were consistent with total and relative concentrations of the three substances. It seems that the low-concentrations endmember functioned as a basis, as it was present with significant abundances in almost all unmixing results. This endmember was usually found in combination with one and sometimes two other endmembers at higher abundances $(>0.25)$ and two endmembers at low abundances $(<0.25)$. The results show a correlation between high abundances of the endmembers dominated by [Chl], [SPM] or $a_{\mathrm{CDOM}}$, and a relatively high concentration for that substance - in comparison to the concentrations of the other two substances. At stations where concentrations are (relatively) comparable, the SPM-dominated endmember has the highest abundance. The last remark is in agreement with general knowledge of the influence of SPM and its spectral signature (e.g. Lubac and Loisel 2007).

\subsection{Water class monitoring with unmixed MERIS data}

The unmixed MERIS images show clear spatial patterns. Spatial variation in the obtained water classes is visible, as shown in Figs. 3, 4, 5, 6, 7 and 8. RMSE values of the figures presented in this section can be found in Appendix 4.

High abundances ( 0.5 to 0.9 ) of the SPM-Chl-dominated endmember were found at the innermost locations of the Wadden Sea and in sheltered areas behind the islands (Fig. 3). This agrees with the trend of much higher concentrations of all three substances in the Wadden Sea than in the North Sea (Hommersom et al. 2009). The basic lowconcentrations endmember showed its highest abundances in the North Sea, in winter covering most of the German Bight (Fig. 4a), while in spring and summer its area was reduced (Fig. 4b) in favour of the CDOM-dominated, CDOM-Chldominated and Chl-dominated endmembers (e.g. Fig. 5). The pure water endmember had low abundances (maximum, 0.5 ; generally, 0.2 or 0.3 ) at the most offshore locations $\left(\sim 53.5^{\circ} \mathrm{N},<5.5^{\circ} \mathrm{E}\right)$ in almost every image (not shown). Only in winter was this endmember spread over the German Bight with abundances reaching maximum values of 0.2 .

As expected, a gradient was found in Ems-Dollard estuary (Fig. 6), with SPM-dominated water in the Dollard
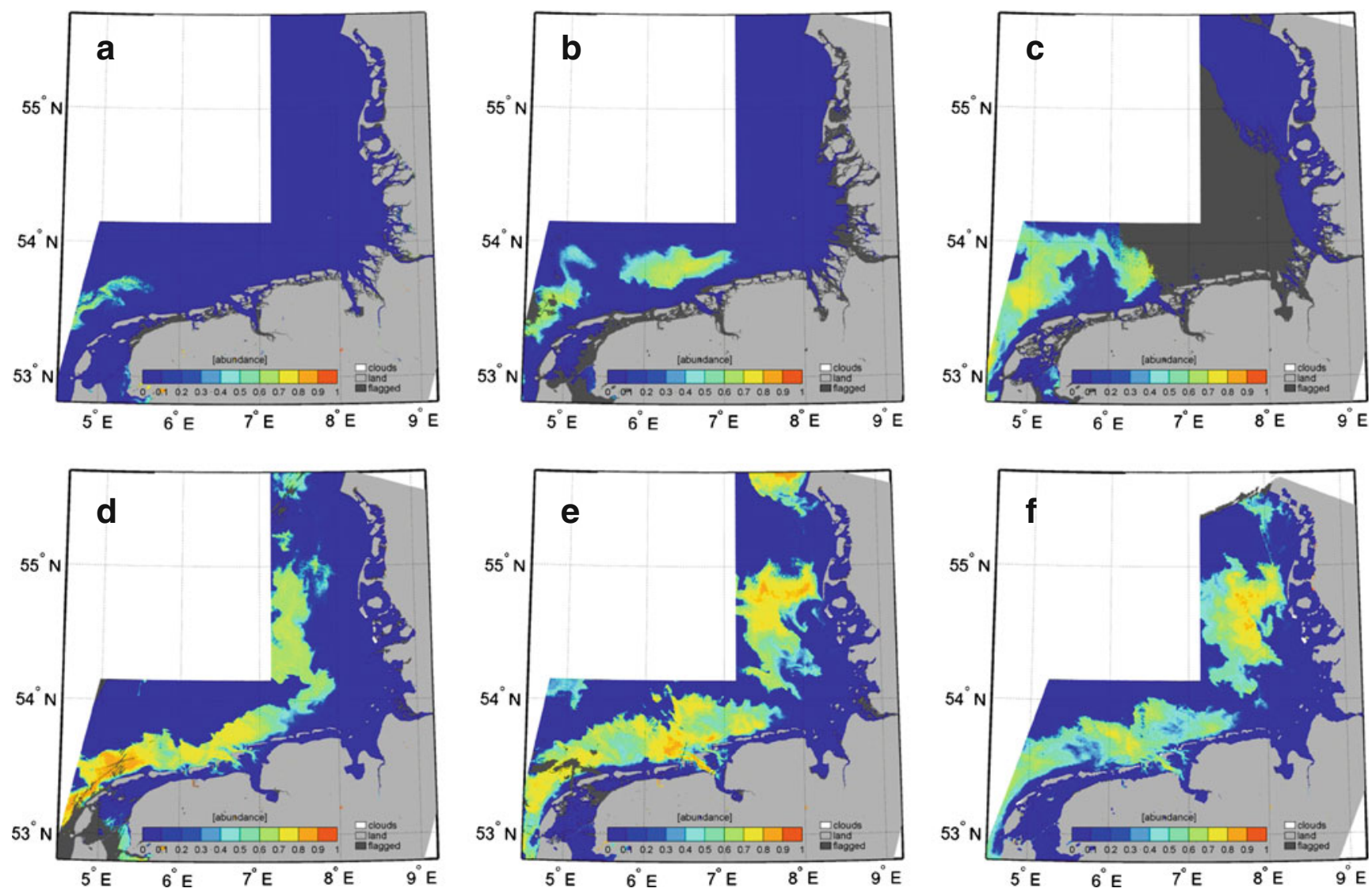

Fig. 5 Development of the spring bloom in 2007, illustrated with abundances of the Chl-dominated endmember. Images of: a March 12th, b March 25th, c March 28th, d April 16th, e April 29th, and f May 1st 
Fig. 6 General trend in the Ems-Dollard estuary, illustrated with the unmixed image of April 16th, 2007. a SPM-dominated endmember, b SPM-Chldominated endmember, $\mathbf{c}$ lowconcentrations endmember, $\mathbf{d}$ Chl-dominated endmember
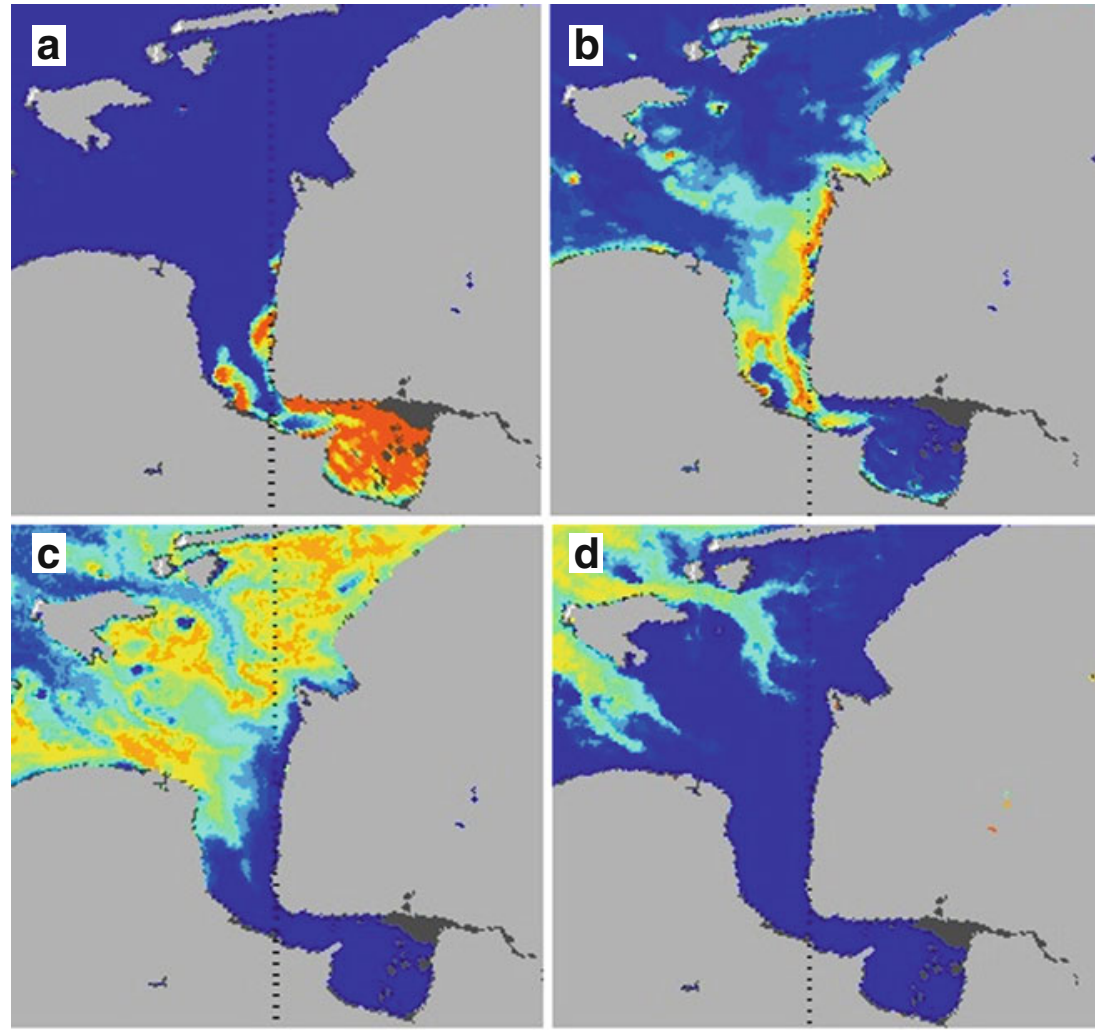

[abundance]

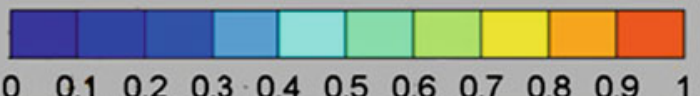

clouds land flagged
(Fig. 6a), via SPM-Chl-dominated water in the inner estuary (Fig. 6b) to high abundances for the low concentrations endmember in the outer estuary (Fig. 6c). In spring, because of phytoplankton blooms (e.g. Cadée 1980), outside the estuary the Chl-dominated endmember was found (Fig. 6d). This spatial trend is similar to the trend found by Magnuson et al. (2004) in the upper, mid and lower Chesapeake Bay and the inshore Middle Atlantic Bight. This trend is characterised as: high $b / a$ values in the upper estuary (very high scattering due to extreme [SPM] and high absorption by $\mathrm{Chl}$ due to high [Chl]), via lower $b /$ $a$ values at high-total $a$ and $b$ in the mid-estuary (high [SPM] and high [Chl]), and again lower $b / a$ values at lowtotal $a$ and $b$ in the lower estuary (low [SPM] and low [Chl]), to finally low $b / a$ values at low $a$ and $b$ (very low [SPM] and low [Chl]) at sea.

Four images, acquired in June and July 2006, with calm weather (average daily wind conditions over the days of acquisition of the four images ranging 2.9-6.1 $\mathrm{ms}^{-1}$, wind direction north-east to south-east) were selected to analyse tidal changes. With these four images half of the tidal cycle was covered. As the tide varies over the area, the part of the cycle that was covered depends on the location (e.g. for the area near Den Helder the images cover high water (HW) to low water $(\mathrm{LW}))$. The expectation was to find higher influence of SPM about $2 \mathrm{~h}$ before slack tide, due to tidal currents (Hommersom et al. 2009; Poremba et al. 1999, Postma 1982). Fig. 7a-d shows the abundances of the SPM-Chl-dominated endmember, which was the most representative endmember in the Wadden Sea in the four selected images. Indeed, over the examined part of the tidal cycle the following trends in the abundances of the SPMChl-dominated endmember were visible (Fig. 7a-d):

- The lowest abundances occurred just after HW, when relatively clear North Sea water had entered the

Fig. 7 Images showing the influence of tidal variation with the abundances of the SPM-Chl-dominated endmember. a-c respectively: July 3rd (10.29 UTC), June 30th (10.23 UTC), June 11th (10.20 UTC), June 8th (10.14 UTC), all 2006. The circles represent the areas of red, Den Helder (DH; the narrow channel); green, the eastern Dutch Wadden Sea (EDWS); yellow, Ems estuary/area near island Borkum (EB); and blue, the East-Frysian Wadden Sea (EFWS, Germany). Tides were ( $H W$ high water, $L W$ low water): a DH HW; EDWS, $\sim 2.5 \mathrm{~h}$ after LW; EB, $\sim 2 \mathrm{~h}$ after LW; EFWS, $\sim 1.5 \mathrm{~h}$ after LW. b DH just after HW; EDWS, $\sim 1.5 \mathrm{~h}$ before HW; EB, $\sim 2.5 \mathrm{~h}$ before HW; EFWS, $\sim 3 \mathrm{~h}$ before HW. c DH $\sim 1.5 \mathrm{~h}$ before LW; EDWS, $\sim 1 \mathrm{~h}$ after HW; EB, $\sim 0.5 \mathrm{~h}$ after LW; EFWS, just after HW. d DH LW; EDWS, $\sim 2 \mathrm{~h}$ before LW; EB, $\sim 3 \mathrm{~h}$ before LW; EFWS, $\sim 2.5 \mathrm{~h}$ after HW 
Wadden Sea and SPM and benthic algae have had the time to settle out (Den Helder, Fig. 7b; the East Frisian Wadden Sea, Fig. 7c).

- Abundances increased during ebb tide (Den Helder, Fig. 7c; Eastern Dutch Wadden Sea, Fig. 7d; Ems
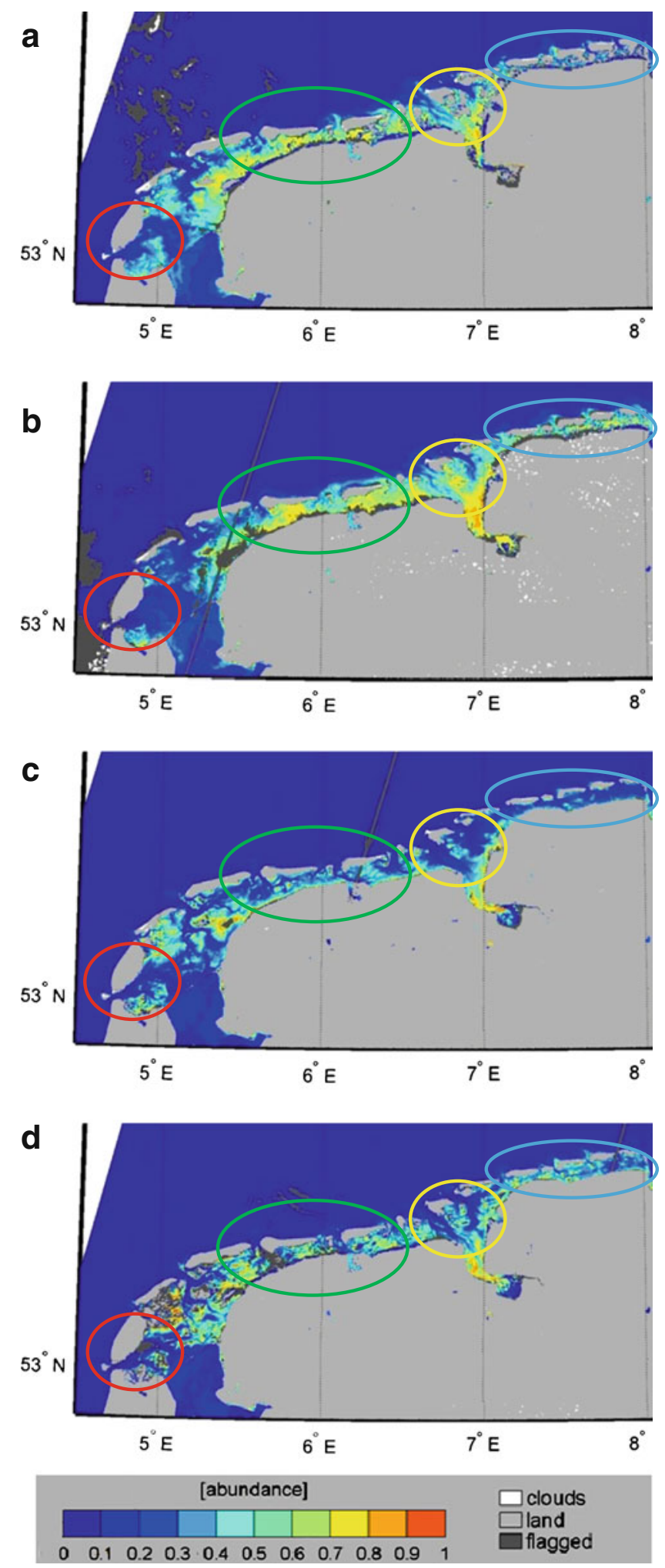

estuary/area near island Borkum, Fig. 7d; East Frisian Wadden Sea, Fig. 7d).

- At LW and the first hour(s) after, large percentages of the surface were covered with surfacing tidal flats. Abundances in the surrounding water were similar to or lower than during ebb (East Frisian Wadden Sea, Fig. 7a; near Den Helder, Fig. 7d). This makes sense, as SPM and benthic algae will be subject to sedimentation in the calm water.

- The highest abundances were seen during flood, about $2.5 \mathrm{~h}$ before HW (Eastern Dutch Wadden Sea, Figs. 7a, b; Ems estuary/area near island Borkum, Fig. 7b).

Seasonal changes became visible in the abundances as well. In winter, the abundances of the CDOM-dominated, CDOM-Chl-dominated and Chl-dominated endmember were reduced to zero, while the abundances of the SPMdominated endmember were relatively high compared with summer (Fig. 8). This could be explained by higher SPMresuspension because of the windier weather (e.g. Lemke et al. 2009; Grossart et al. 2004) and a lack of benthic organisms that stabilise the sediment (Austen et al. 1999). Because of many days with clear weather in (early) spring 2007, results could show the appearance, development and movement of the spring bloom of phytoplankton (e.g. Cadée 1980), in March-May 2007 (Fig. 5). The bloom drifted in the direction of the residual current in the German Bight (Postma 1982). Unfortunately, May 2007 was very cloudy so that this bloom could not be followed further.

Wind induced resuspension, as seen by for example Stanev et al. (2009) and Badewien et al. (2009), became visible through high abundances of the SPM-Chldominated endmember (Fig. 9a, b) and the SPMdominated endmember (Fig. 10a, b) in the Wadden Sea and on the outer side of the islands. Abundances of these endmembers were much lower during calm weather (Fig. 3). The south-westerly wind at December 10th 2006 had apparently blown relatively clear North Sea water into the western Dutch Wadden Sea (low abundances of the SPM-Chl-dominated endmember), while resuspension (due to wind waves and/or tide against wind) caused relatively high abundances of the SPM-Chl-dominated and SPMdominated endmembers in the rest of the Wadden Sea, and north of the Dutch and western German islands (Figs. 9a and $10 \mathrm{a}$ ). Waves reach the bottom at shallow locations, including the tidal flats, while at other locations mixing increases. As the Wadden Sea is always well mixed (Postma, 1982), due to tidal changes, water masses of shallow and deep locations easily mix, so resuspended matter can move over relatively large areas. The northnorth-easterly wind of late March 2007 caused much higher resuspension than the south-westerly wind early December 

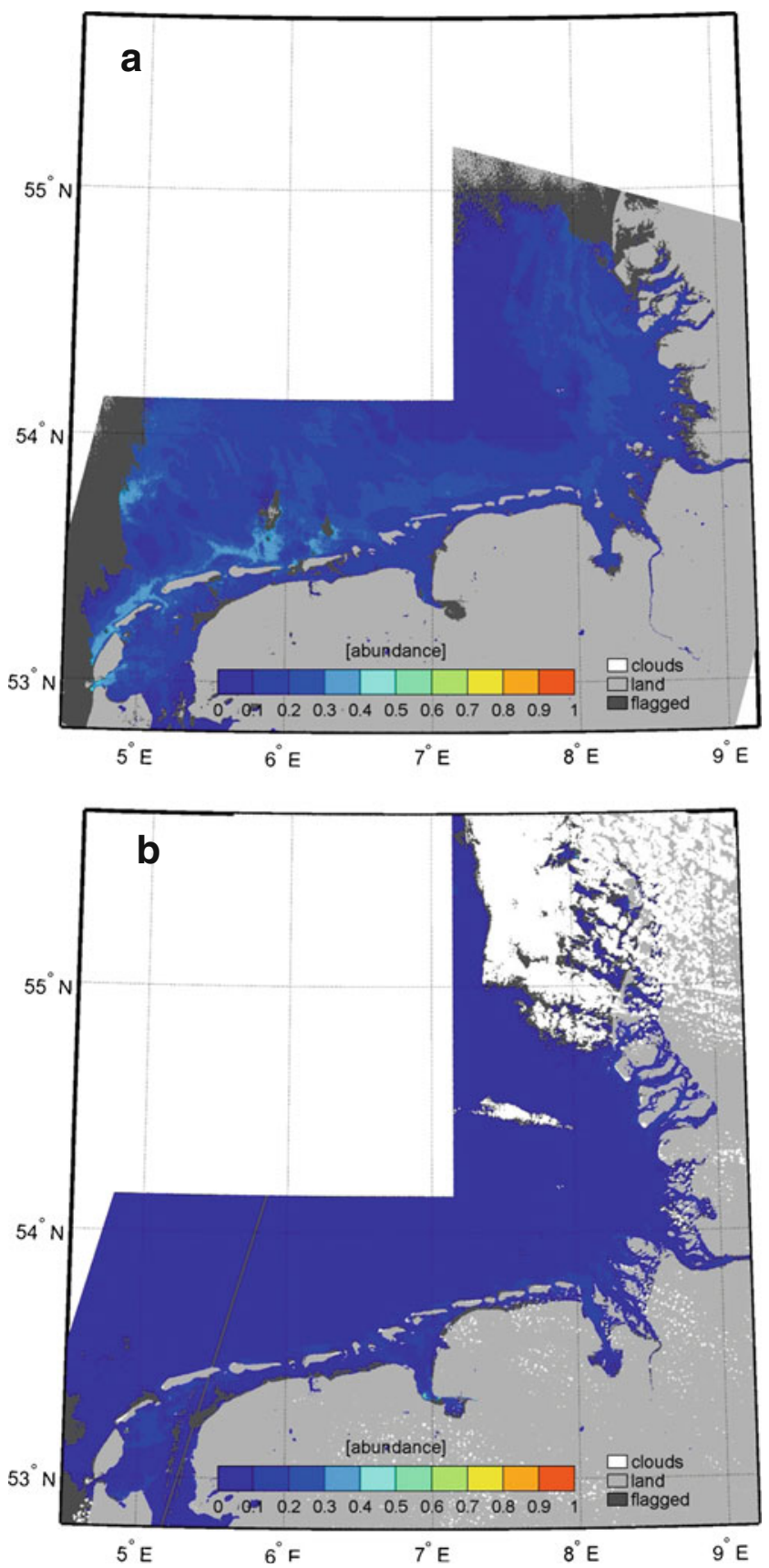

Fig. 8 Abundance of the SPM-dominated endmember: a in winter, illustrated with the image of January 16th 2006 (daily average southeasterly wind $6.8 \mathrm{~ms}^{-1}$, highest hourly average wind $8.0 \mathrm{~ms}^{-1}$ ), which could not be processed with the ICOL processor; b in summer, illustrated with the image of June 30th 2006 (daily average northeasterly wind $6.1 \mathrm{~ms}^{-1}$, highest hourly average wind $9.0 \mathrm{~ms}^{-1}$ )

2006, visible as very high abundances of the SPM-Chldominated endmember and relatively high abundances of the SPM-dominated endmember along the Northern German and Danish islands in the German Bight (Fig. 9b). The wind-wave-induced mixing kept the sediment in the EastAnglian plume (Eleveld et al. 2008; Doerffer and Fischer
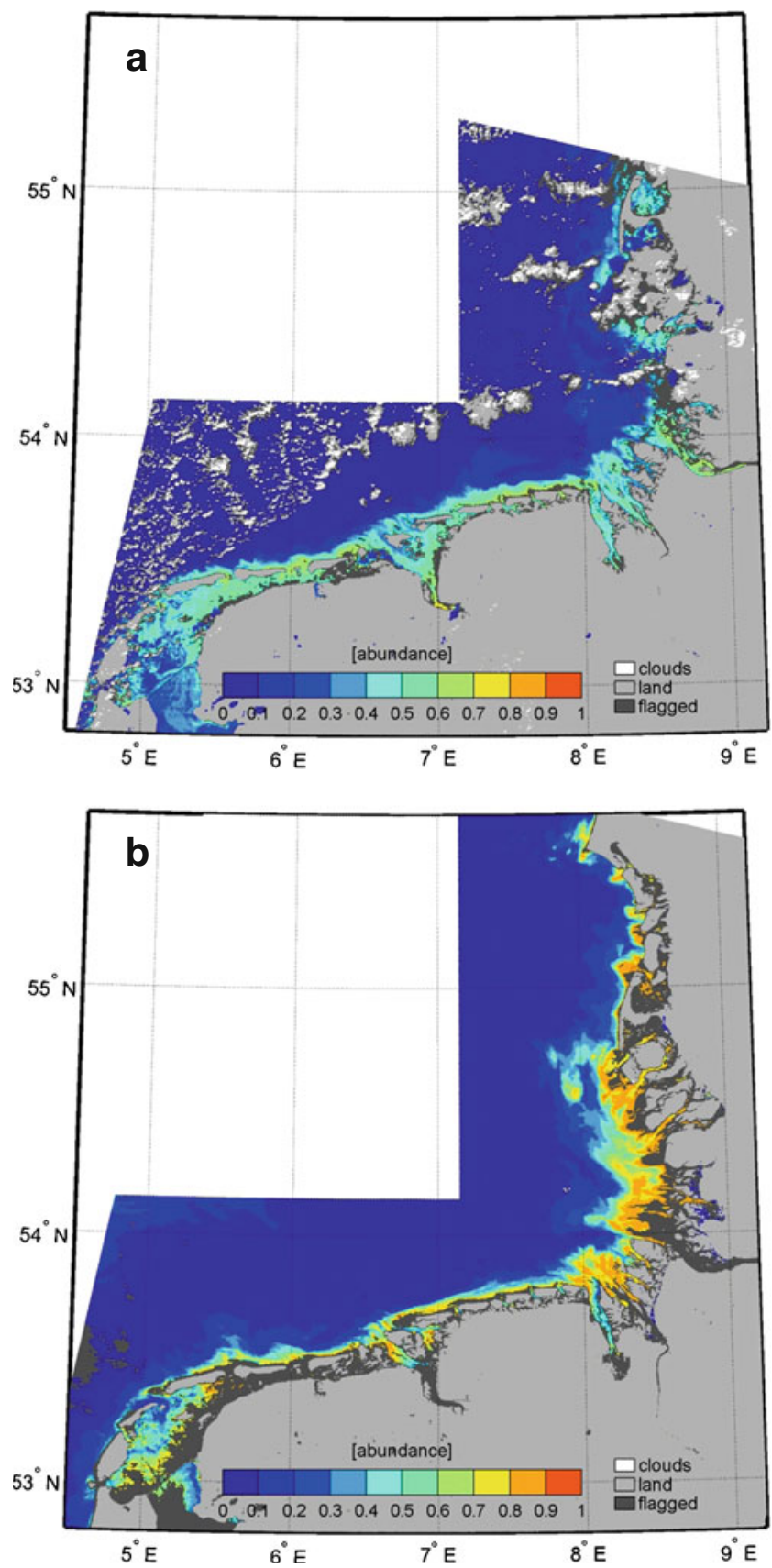

Fig. 9 Influence of wind on the abundances of the SPM-Chldominated endmember. a South-westerly wind, illustrated with the image of December 10th 2006 (low tide in the Marsdiep), after 8 days south-westerly wind (daily average wind, $5.3-12.4 \mathrm{~ms}^{-1}$; highest hourly average wind, $7.0-15.0 \mathrm{~ms}^{-1}$; December 8 th-11th had the lowest wind speeds). This image could not be processed with the ICOL processor. b North-north-easterly wind, illustrated with the image of image March 25th 2007, after 5 days strong wind (daily average wind, $10.9-13.8 \mathrm{~ms}^{-1}$; highest hourly average, $11.0-16.0 \mathrm{~m}$ $\mathrm{s}^{-1}$, on March 25th itself wind turned to East and decreased)

1994) in suspension, which is visible as high abundances of the SPM-Chl-dominated and the SPM-dominated endmembers in the image of March 25th, north of $54.5^{\circ} \mathrm{N}$ and west of $6^{\circ} \mathrm{E}$ (Figs. 9b and 10b). 

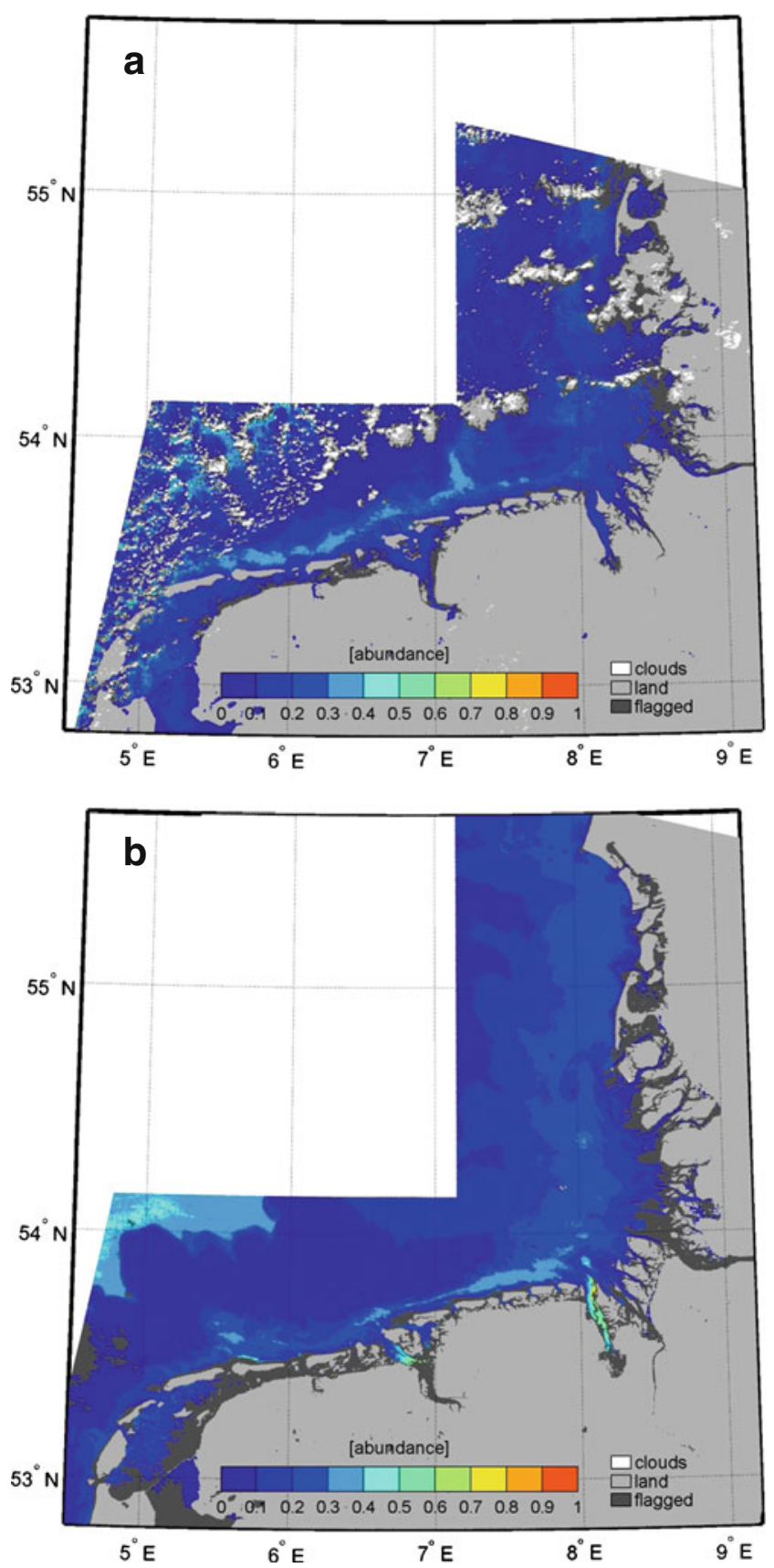

Fig. 10 Same as Fig. 9, now presenting the abundance of the SPMdominated endmember

Early in July 2006, a patch with a high abundance of the SPM-dominated endmember was seen north-west of the Danish islands (Fig. 11a), indicating high SPM, or at least high reflectances. Also the pure-water endmember was elevated. The shape and location of the patch, the low-wind conditions of July 3rd and the combination with the pure-water endmember reveal that the patch could not be caused by resuspension and the high reflectances would possibly be caused by something else than SPM. Elevated RMSE values in the patch (Fig. 11b) suggest the MERIS spectra had a shape that was not well covered by the spectral shapes of the endmembers: the patch was a novelty (Schiller et al. 2007). It could be a coccolith bloom, as these algae cause a high reflection and have a distinct specific absorption spectrum. This explanation was supported by the presence of an elevated biomass of prymnesiophytes (coccoliths) found by the Danish National Environmental Monitoring Institute (NERI: www.dmu.dk/International/Water/MarineMonitoring/MADS) at the nearest in situ station in the first 2 weeks of July 2006. The spectral shape of the reflectances in the patch showed high similarities with the bloom found by
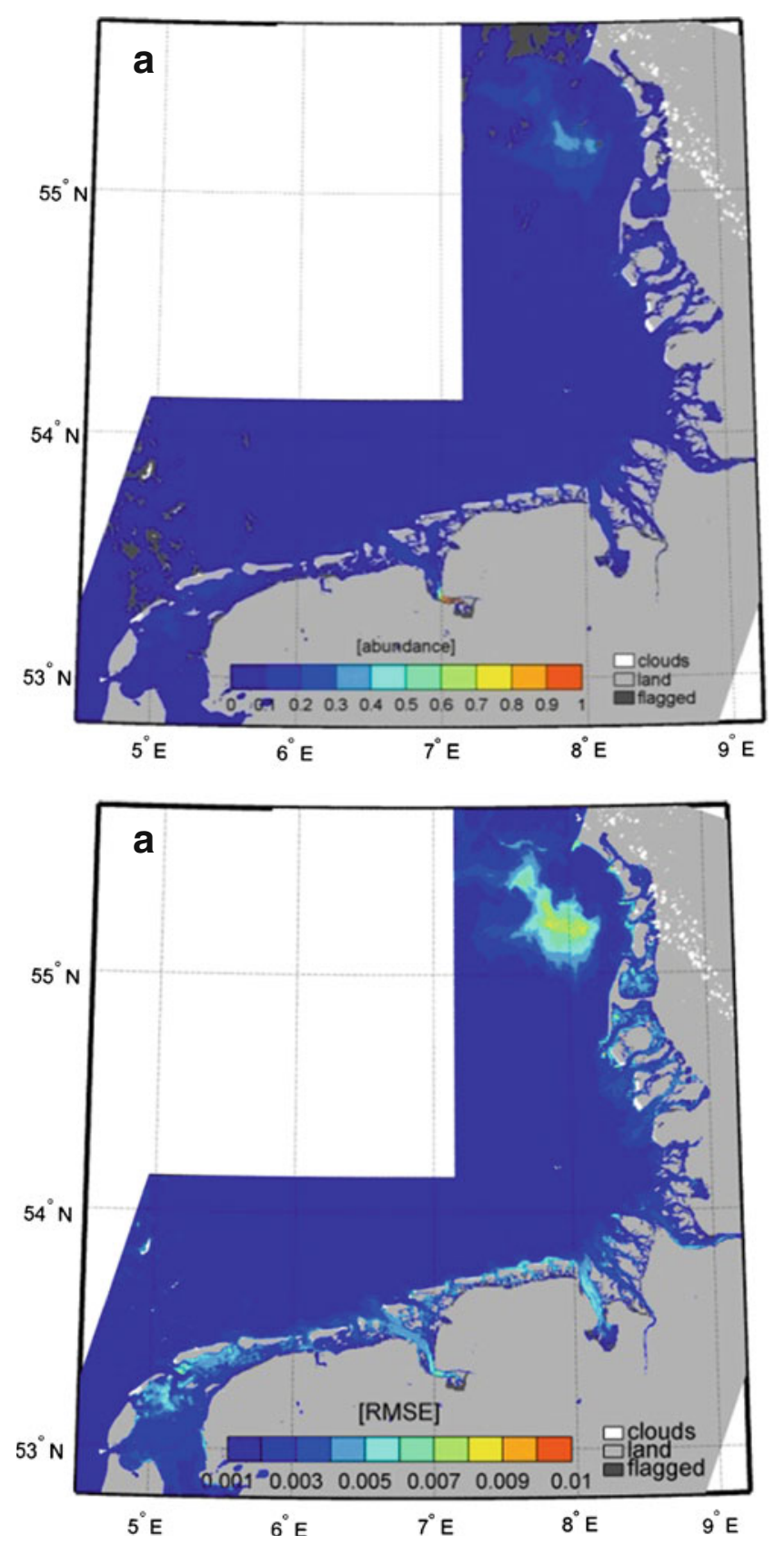

Fig. 11 Abundance of the SPM-dominated endmember, July 3rd 2006 
Schiller et al. (2007); the high blue-green ratios explains why the pure-water endmember had high abundances.

Tidal flat detection would in principle be possible as well with the presented unmixing method. To do this, a 'tidal flat'endmember should be included. But unfortunately, the neural network of the $\mathrm{C} 2 \mathrm{R}$ processor was not trained for land or tidal flat data, and all pixels at land or tidal flat are flagged with the RAD_ERR flag, which means that the reflection at the top of the atmosphere was invalid and reflectances should not be trusted. The C2R level-2 product used in this study indeed showed unrealistically low values at tidal flats and land, so that unmixing did not give high abundances for a tidal flat endmember for these pixels. As an alternative, standard MERIS level-2 data were tested, but it was found that they often have negative values in the blue wavelengths or showed unrealistic spectral shapes in near-coastal waters. Therefore, this data have not been used as modelling input.

\subsection{Uncertainty}

Changes in concentration settings during endmember generation were found to lead to small changes in endmember abundances. As shown in Fig. 12, changes in concentrations of $10 \%$ during endmember generations resulted in almost $1: 1$ correlations of abundances, shown for the low-concentrations endmember and the SPM-Chl-dominated endmember. The expectation is that the model is also relatively invulnerable for small changes in shape of the SIOPs $\left(a^{*}{ }_{\mathrm{Chl}}, a^{*} \mathrm{SPM}\right.$, $a^{*}{ }_{\mathrm{CDOM}}$, and $b^{*}{ }_{\mathrm{SPM}}$ ) used in the Gordon model.

The RMSE data presented in Appendix 4 show that RMSE values are generally $<0.005$ and always $<0.01$. As the modelled abundances are presented on a scale from 0 to 1 with steps of 0.1 , the error is always $<10 \%$ relative to the results. Appendix 4 also shows that the shape of the RMSE does not follow patterns in abundances of certain endmembers.

It appeared that ICOL (first version) processing failed for some images. Out of 32 selected images, two images acquired in winter 2006 (Jan 16th and Dec 10th) could not be processed due to an unknown reason. As images without too much cloud cover were scarce, these two were still used with only $\mathrm{C} 2 \mathrm{R}$ processing. Since ICOL compensates for the adjacency effect, the influence of ICOL is significant in water pixels nearby land covered with vegetation. Our experience is that ICOL has a large influence on MERIS data processed with the standard MERIS processor, but the effect is negligible for most of the Wadden Sea when images are processed with the $\mathrm{C} 2 \mathrm{R}$ processor. This could be explained by the fact that MERIS standard level 2 atmospheric correction relies for a large part on observed reflectances in the near infrared, the part of the spectrum which is most heavily influence by the adjacency effect. $\mathrm{C} 2 \mathrm{R}$ on the other hand uses a neural network that uses all spectral bands. Influence of ICOL on C2R data is expected
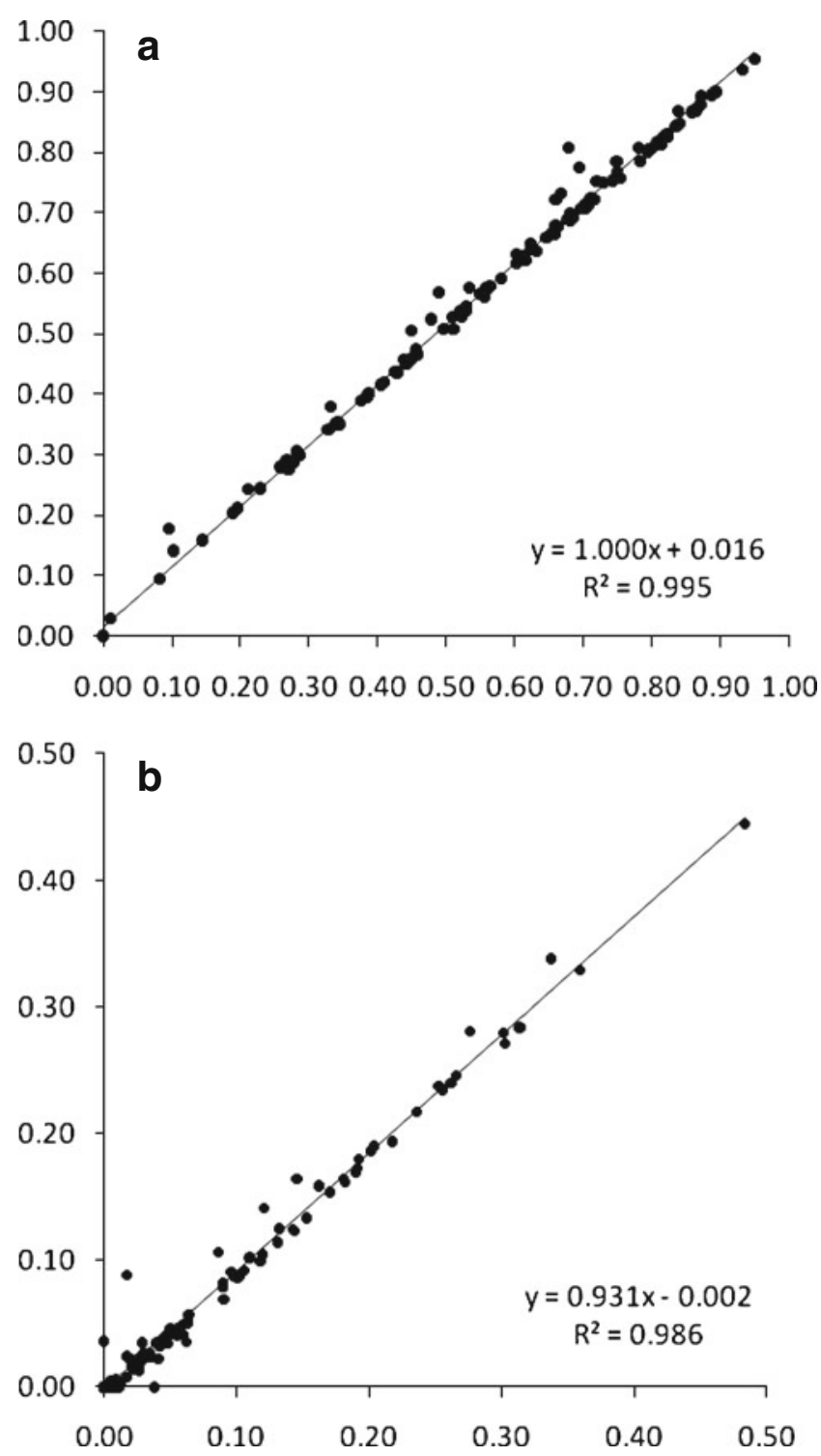

Fig. 12 Results of the error analysis. a The horizontal axis represents the abundance of the low-concentrations endmember is shown endmember obtained with processing the in situ reflectances (as in Table 2). The vertical axis represents the abundance of the same endmember, obtained after processing the same TriOS data with a model in which all endmembers were generated with $10 \%$ higher concentrations for all three substances. b Same as for (a), now for the Chl-SPM-dominated endmember

in the inner parts of the Ems estuary (Dollard) and in the pixels bordering the coast.

\section{Conclusions}

A method was developed for water classification and monitoring by means of fully constrained unmixing of (MERIS) reflectance spectra. The model can be applied to a broad range of coastal areas and easily be adapted to areas 
with different SIOPs. It can be used to monitor water quality in surface water (Chl, SPM and CDOM) and study changes in time and space. Advantage of this type of model over other classification models is its fuzziness, which is better suited to visualise degradation, settling and mixing of (substances in) water masses than other classification models.

A disadvantage of the presented model, as compared with models that retrieve concentrations, is that abundances (based on IOPs) are only approximately related to absolute concentrations, as the effects of Chl $a$, SPM and CDOM concentrations on reflectance spectra are non-linear. However, monitoring requires an objective and standardised technique, which allows comparison of data of one place or moment to that of next day, or to that of another location. This objective is achieved with the presented endmember model. The variations in retrieved in water classes were in agreement with expected spatial-, tidal-, seasonal- and wind-related variations.

A coccolith bloom was identified as a novelty by a combination of high reflectance values and a high RMSE at a location where this was not expected. An extra 'coccolith' endmember might be included to directly identify such blooms. For application to other ocean colour sensors (with enough spectral bands to distinguish Chl $a$ and SPM absorption) or locations with different SIOPs, the endmembers need to be re-simulated. Simulation of a new set of endmembers is easier than acquiring local SIOP sets or recalibrating semi-empirical models as it requires only a few in situ measurements of the specific absorption and scattering properties.

Acknowledgements Scott Gillespie is gratefully thanked for English editing. Raul Zurita-Milla is thanked for his advice on the programming of the unmixing model. The captain and crew of the Royal Netherlands Institute for Sea Research R.V. Navicula, Kristi Valdmets and Hamza el Abida are thanked for their help during the fieldwork. The Institute for Environmental Studies laboratory is thanked for their expertise on chlorophyll analysis. Wind data were provided by the Royal Netherlands Meteorological Institute. MERIS data were provided by the European Space Agency. Phytoplankton data off the Danish coast were provided by the Danish National Environmental Monitoring Institute. This project is financed by NWO/SRON Programme Bureau Space Research the Netherlands.

Open Access This article is distributed under the terms of the Creative Commons Attribution Noncommercial License which permits any noncommercial use, distribution, and reproduction in any medium, provided the original author(s) and source are credited.

\section{Appendix 1-MERIS data}

MERIS FR level 1 data (processor version IPF 5.05/ MEGS7.4, ESA, 2009) were prepared in the software Basis ERS \& ENVISAT (A)ATSR and MERIS (BEAM). Firstly, data was processed with the 'Improved Contrast between Ocean and Land' processor (ICOL) to reduce the adjacency effects (Santer and Zagolski 2009). Next, the data were processed with the Case-2 Regional processor (C2R) for atmospheric correction (Doerffer and Schiller 2006a, 2006b). The ICOL and C2R processors apply their own land, cloud and quality flags (Santer and Zagolski 2009; Doerffer and Peters 2006). The standard C2R land flag was tightened to 'toa_reflec_10>toa_reflec_6' (which means that data are flagged as land if the Top Of the Atmosphere ('TOA') reflection is larger at band 10 than at band 6). Cloud flagging was done with the L1 flags, because the tightened C2R-land flag sometimes misinterpreted clouds as land. Pixels with one or more raised C2R quality flags (RAD_ERR (radiance error), TOSA_OOR (top of standard atmosphere out of range), WLR_OOR (water-leaving radiance out of range) and ATC_OOR (atmospheric correction out of range)) were not used as input for the endmember model. MERIS images with low cloud cover over the Wadden Sea were selected from the years 2006 and 2007.

\section{Appendix 2-endmember selection}

The selection of a pure set of endmembers is an important part of the unmixing model. endmembers can be derived from in situ ground truth measurements or from images with several methods, for example:

- Manual selection, based on expert knowledge. This method is fast and easy, however, it is not objective. Another problem is that all endmembers should be available in the database. The study of Martin Traykovski and Sosik (2003) used expert knowledge to define their classes, although these were not used for endmember modelling.

- Pure pixel method. All pixels of an image are placed in a scatter plot with on both axes a wavelength. This is repeated while varying the wavelengths. Spectra that occur most often at the outer places of the scatter plots are selected as endmembers. This method is objective, however, in sea (almost) no pure spectra can be found, and endmembers defined with this method will vary per image, season etc. The study of Tyler et al. (2005) selects endmembers with this method; Zortea and Plaza (2009) present an improved pure pixel method for land remote sensing data.

- Classification (for example with K-means clustering). This method is also objective; however, although the cluster centres represent water classes, they do not represent extremes and therefore not endmembers. Tests for the current study indicated that clustering was mainly driven by SPM. Lubac and Loisel (2007) already mentioned that particle backscattering is the prime parameter for the spectral shape. Jianguang et al. (2007) reduced this problem by using a normalised and 
a differentiated spectrum. The disadvantage of this method is that these transformations reduce the possibilities to monitor water classes dominated by SPM.

- Distance analysis. In contrast to classification, this method will identify the outer points as endmembers. However, when more pixels or measurements are available representing an extreme, they are, compared with each other, not seen as extremes anymore.

- Simulation of 'pure' spectra. Another objective method, however, the simulations require a model and prior knowledge, or assumptions about the optical properties in the area (Appendix 3).

An endmember model can be run with more or with less endmembers than the number of spectral bands. However, with more endmembers the model is over determined; there is not one unique solution and the vulnerability for ambiguity increases.

An endmember model can theoretically be run without constrains (Eqs. 2 and 3). However, tests with unconstrained linear unmixing were found to lead to high ambiguity and unrealistic combinations of positive and negative abundances. Also abundances higher than $100 \%$ were found in these tests. For example, a reflectance spectrum with a high reflection should obviously be unmixed with a high abundance of the SPM-dominated endmember, as SPM is the substance causing high reflection. However, when the abundances are not forced to sum to one, the model could also provide $500 \%$ of (low reflecting) CDOM-endmember as a solution, which does not make any scientific sense. To avoid such problems, a linear fully constrained method was applied.

\section{Appendix 3-Gordon model and IOP/SIOP equations}

Endmembers were generated with the Gordon model (Eq. 5), in combination with equations for the total backscattering (Eq. 6) and total absorption (Eq. 7). The remote sensing reflectance Rrs, defined as the above water-leaving radiance divided by the total downward irradiance is strongly wavelength dependent, and was calculated for the nine wavelength bands in the model.

$$
\begin{aligned}
\operatorname{Rrs}= & f\left(b_{\mathrm{b}} /\left(a+b_{\mathrm{b}}\right)\right) /\left(\mathrm{Q} 1.33^{2}\right) \\
b_{\mathrm{b}}(\lambda)= & \left(b_{\mathrm{w}}(\lambda)\right) / 2+b_{\mathrm{SPM}}^{*}(\lambda) B[\mathrm{SPM}] \\
a(\lambda)= & a_{\mathrm{w}}(\lambda)+a_{\mathrm{Chl}}^{*}(\lambda) \times[\mathrm{Chl} a]+a_{\mathrm{SPM}}^{*}(\lambda) \times[\mathrm{SPM}] \\
& +a_{\mathrm{CDOM}}^{*}(\lambda) a_{\mathrm{CDOM}}(440)
\end{aligned}
$$

In Eq. 5, the constant $\mathrm{f}$ was assumed to be 0.33 (Morel and Prieur 1977) and the constant Q that relates upwelling radiance to irradiance was assumed to be equal to $\pi . b_{\mathrm{b}}$ is the total backscattering coefficient $\left(\mathrm{m}^{-1}\right)$, which is a function of $b_{\mathrm{w}}\left(\mathrm{m}^{-1}\right)$, the scattering coefficient for water, $b_{\text {SPM }}^{*}\left(\mathrm{~m}^{2} \mathrm{~g}^{-1}\right)$, the specific scattering for SPM, and $B$, the backscattering to scattering ratio. $B$ was assumed to be 0.03 (Brando et al. 2008; Oubelkheir et al. 2006; Dekker et al. 2001; Loisel et al. 2007). The total absorption coefficient (a) is a function of $a_{\mathrm{w}}\left(\mathrm{m}^{-1}\right)$, the absorption of water, $a^{*}{ }_{\mathrm{Chl}}\left(\mathrm{m}^{2} \mathrm{mg}^{-1}\right)$, the chlorophyll specific absorption coefficient for pigments, $a^{*}{ }_{\text {SPM }}\left(\mathrm{m}^{2} \mathrm{~g}^{-1}\right)$, the specific absorption coefficient for particles, and $a^{*}{ }_{\mathrm{CDOM}}$, the absorption coefficient for CDOM normalised at $440 \mathrm{~nm}$. [Chl] is the concentration of Chl $a\left(\mathrm{mg} \mathrm{m}^{3}\right)$, [SPM] the concentration of SPM $\left(\mathrm{g} \mathrm{m}^{3}\right)$ and $a_{\mathrm{CDOM}}$ the CDOM absorption at $440 \mathrm{~nm}\left(\mathrm{~m}^{-1}\right)$. For these properties the median values of $a^{*}{ }_{\mathrm{Chl}}, a^{*}{ }_{\mathrm{SPM}}, a^{*}{ }_{\mathrm{CDOM}}$, and $b^{*}{ }_{\mathrm{SPM}}$ from the 25 best stations as measured in the Wadden Sea were taken (Hommersom et al. 2009). Data from Pope and Fry (1997) and Morel et al. (2007) were used for absorption properties of pure water $\left(a_{\mathrm{w}}\right)$ and data from Buitenveld et al. (1994) were used for the scattering properties of pure water $\left(b_{\mathrm{w}}\right)$. The refractive index between water and air was assumed to be 1.33 .

\section{Appendix 4-RMSE plots of all unmixed MERIS data}

Figures 13, 14, 15, 16, 17, 18 and 19.

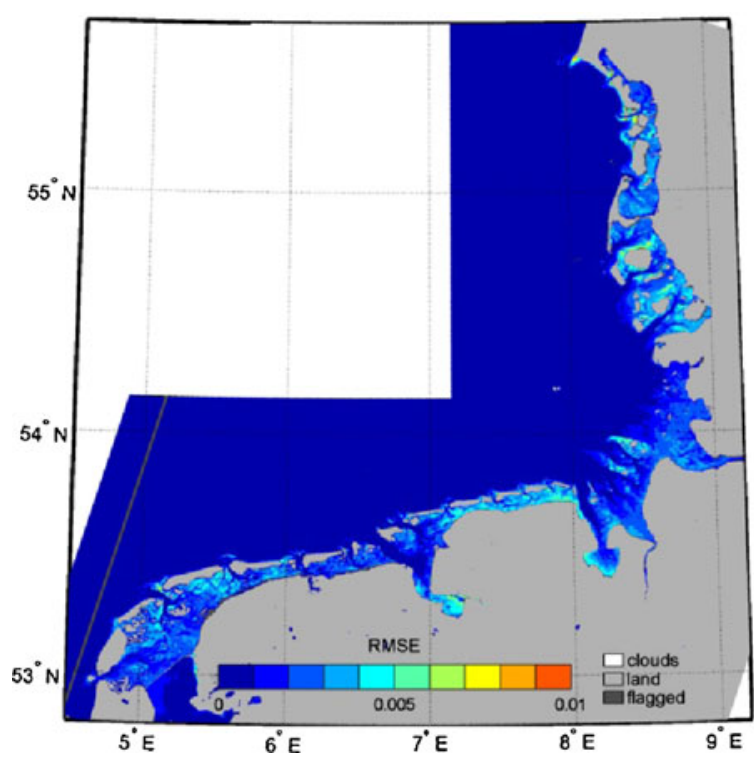

Fig. 13 RMSE of the data presented in Fig. 3, image of May 10th 2006 

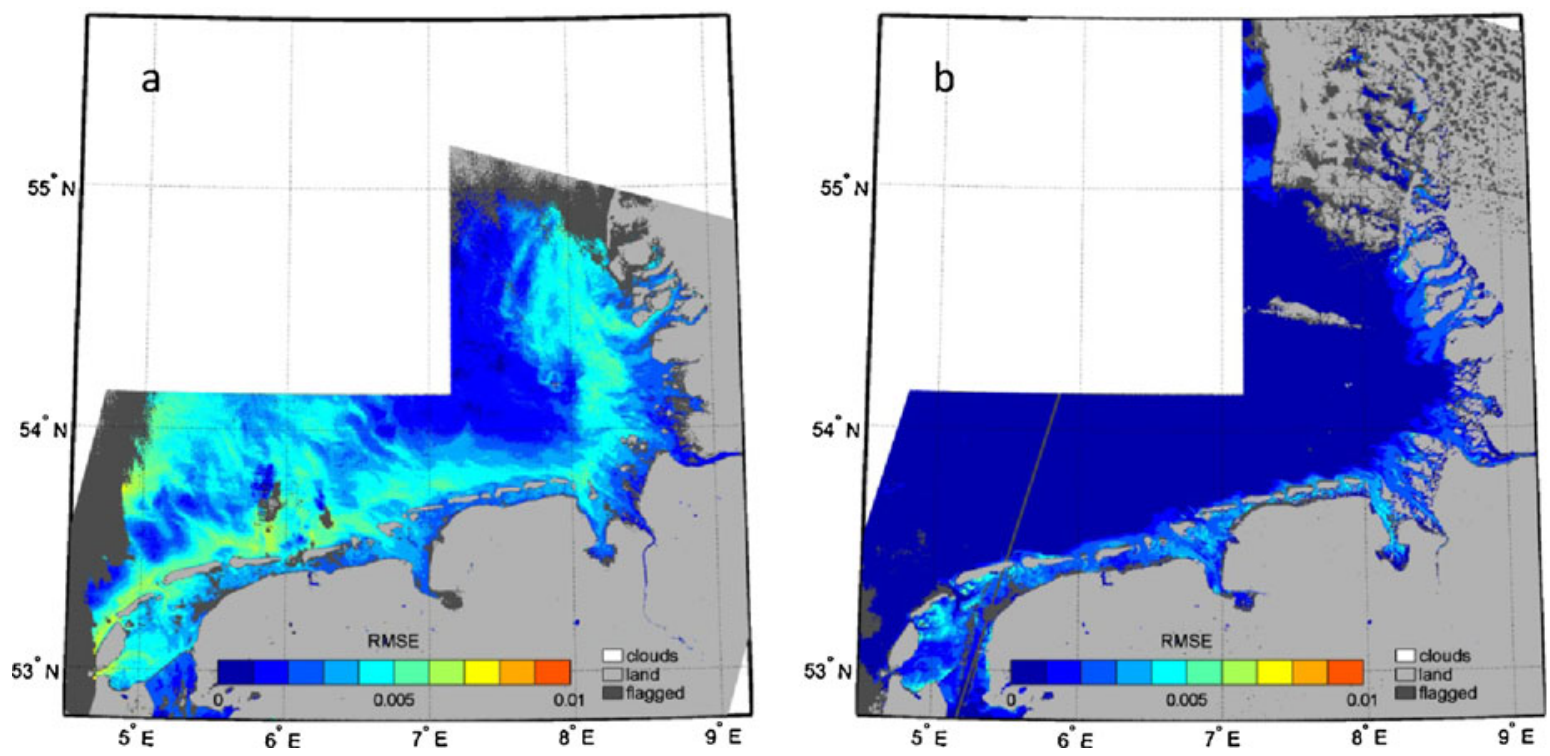

Fig. 14 RMSE of the data presented in Fig. 4. a Image of January 16th 2006, b image of June 30th 2006
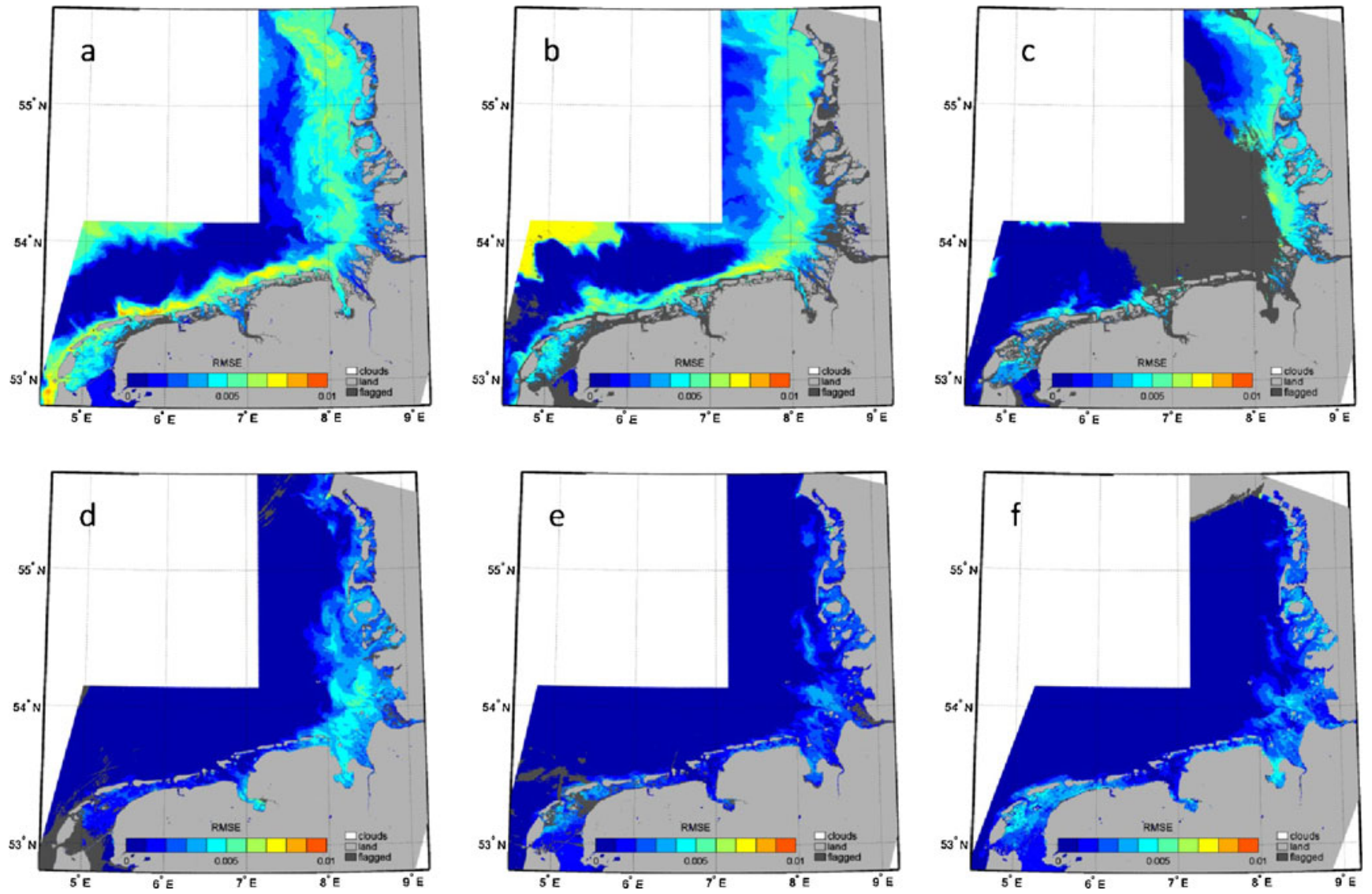

Fig. 15 RMSE of the data presented in Fig. 5. Images of: a March 12th, b March 25th, c March 28th, d April 16th, e April 29th, and f May 1 st 


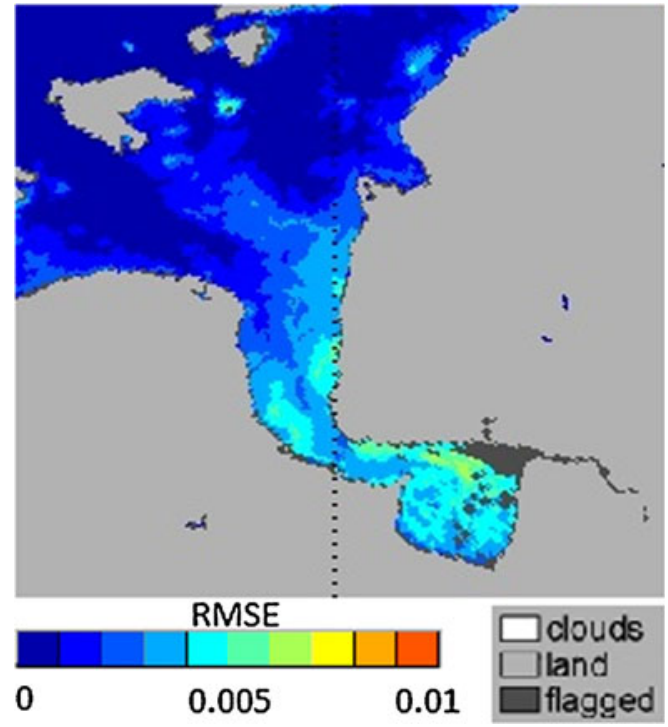

Fig. 16 RMSE of the data presented in Fig. 6. Image of April 16th

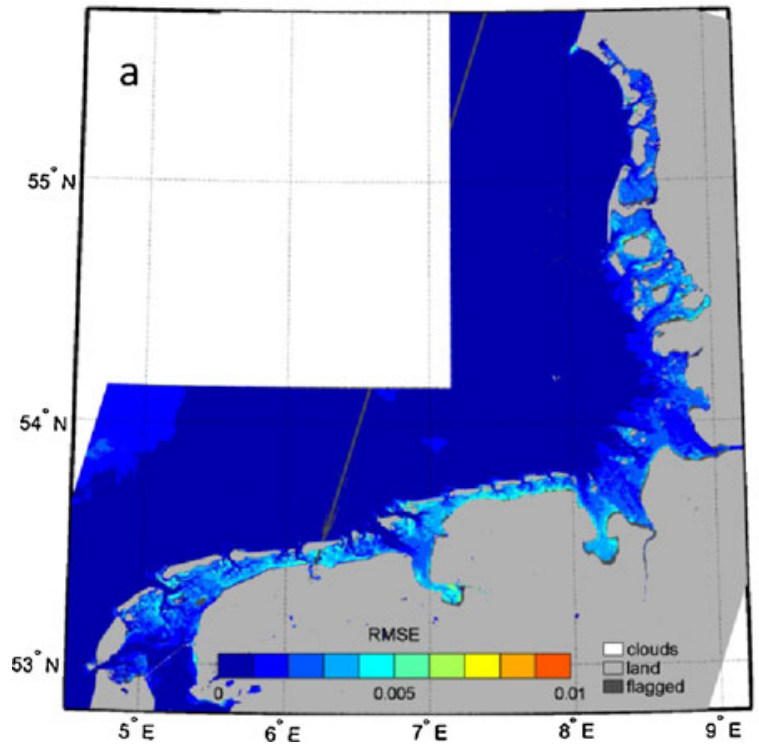

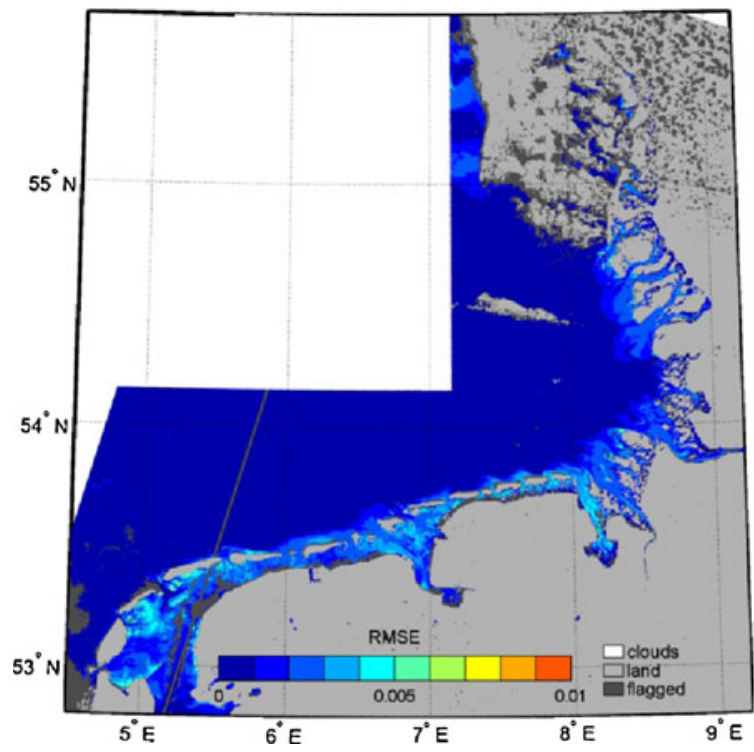

Fig. 18 RMSE of the data presented in Fig. 8. RMSE of the image of January 16th can be found in Fig. 14a. Presented here is the RMSE of the image of June 30th 2006

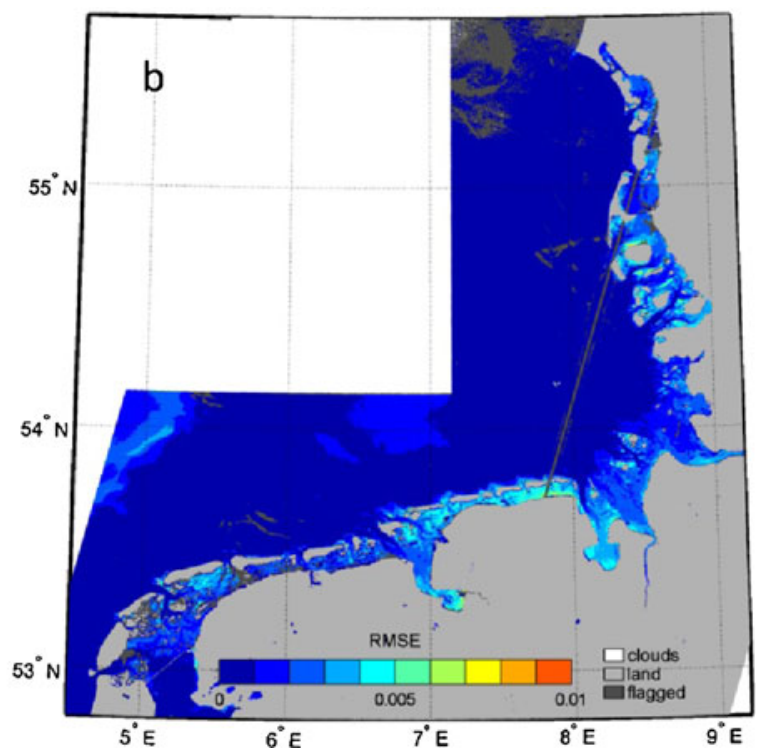

Fig. 17 RMSE of the data presented in Fig. 7. RMSEs of the image of July 3rd can be found in Fig. 11, RMSE of the image of June 30th can be found in Fig. 14. Presented here is the a RMSE of the image of July 11th and the b RMSE of the image of June 8th 

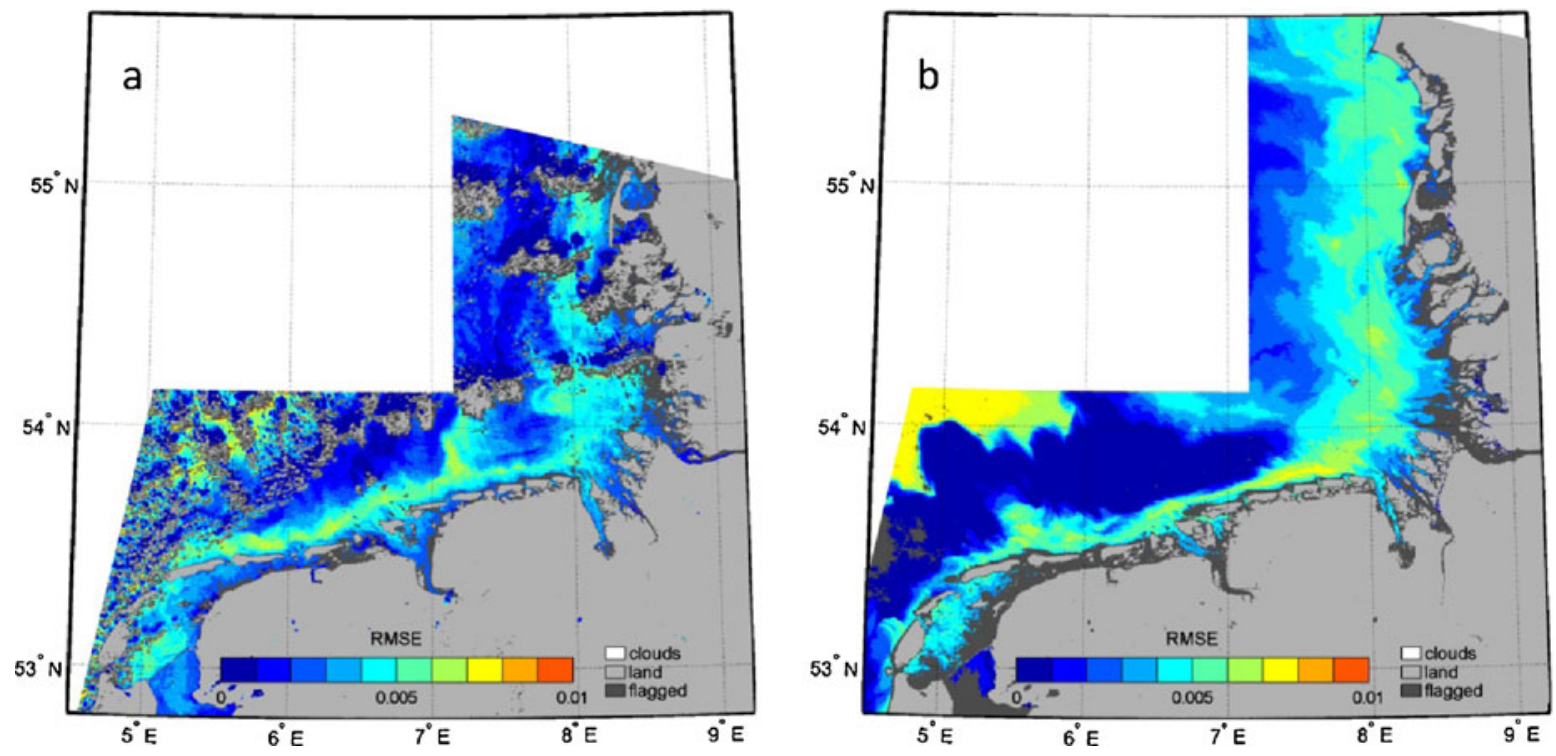

Fig. 19 RMSE of the data presented in Figs. 9 and 10. a Image of December 10th 2006 and b image of image March 25th 2007

\section{References}

Asner GP, Heidebrecht KB (2002) Spectral unmixing of vegetation, soil and dry carbon cover in arid regions: comparing multispectral and hyperspectral observations. Int $\mathrm{J}$ Remote Sens 23:3939-3958

Austen I, Andersen TJ, Edelvang K (1999) The influence of benthic diatoms and invertebrates on the erodibility of an intertidal mudflat, the Danish Wadden Sea. Estuar Coast Shelf Sci 49:99111

Badewien TH, Zimmer E, Bartholomä A, Reuter R (2009) Towards continuous long-term measurements of suspended particulate matter (SPM) in turbid coastal waters. Ocean Dyn 59:227-238

Blondeau-Patissier D, Tilstone GH, Martinez-Vicente V, Moore GF (2004) Comparison of bio-physical marine products from SeaWiFS, MODIS and a bio-optical model with in-situ measurements from Northern European waters. J Opt A Pure Appl Opt 6:875-889

Brando VE, Dekker AG, Schroeder Th, Park YJ, Clementson L.A., Steven A, Blondeau-Patissier D (2008) Satellite retrieval of chlorophyll CDOM and NAP in optically complex waters using a semi-analytical inversion based on specific inherent optical properties. A case study for Great Barrier Reef coastal waters. In: Proceedings of the Ocean Optics conference XIV, Italy. CDROM. p. 10

Buitenveld H, Hakvoort JHM, Donze M (1994) The optical properties of pure water. In: Proceedings of the SPIE, vol. 2258. pp. 174183

Cadée GC (1980) Reappraisal of the production and import of organic carbon in the Western Wadden Sea. Neth J Sea Res 14:305-322

Dekker A, Brando VE, Anstee JM, Pinnel T, Kuster H, Hoogenboom H, Pasterkamp R, Peters S, Vos O, Malthus T (2001) Imaging spectrometry of water, chapter 11. pp. 307-359. In: van der Meer $\mathrm{F}$, and de Jong $\mathrm{S}$ (eds) Imaging spectrometry: basic principles and prospective applications: remote sensing and digital image processing. Kluwer, Dordrecht
Doerffer R, Fischer J (1994) Concentrations of chlorophyll, suspended matter, and gelbstoff in case II waters derived from satellite coastal zone color scanner data with inverse modeling methods. J Geophys Res Oceans 99:7457-7466

Doerffer R, Murphy D (1989) Factor analysis and classification of remotely sensed data for monitoring tidal flats. Helgoländer Meeresuntersuchungen [Helgoland Marine Research] 43:275-293

Doerffer R, Peters M (2006) Algorithm Theoretical Basis Document MERIS Case II ATBD-ATMO-MERIS Regional Case 2 Water BEAM Extension. Flags ATBD. Version 1.1 16. p. 5

Doerffer R, Schiller H (2006a) Algorithm Theoretical Basis Document MERIS Case II ATBD-ATMO MERIS Regional Case 2 water BEAM extension atmospheric correction ATBD. Version 1.1, 24. p. 25

Doerffer R, Schiller H (2006b) Algorithm Theoretical Basis Document MERIS Regional Case 2 water BEAM extension performance of the atmospheric correction part: sun glint correction. MERIS Case 2 ATMO-Test. p. 14

Doxaran D, Cherukuru RCN, Lavender SJ (2005) Use of reflectance band ratios to estimate suspended and dissolved matter concentrations in estuarine waters. Int J Remote Sens 26:1763-1769

Doxaran D, Cherukuru RCN, Lavender SJ (2006) Apparent and inherent optical properties of turbid estuarine waters: measurements, empirical quantification relationships, and modeling. Appl Opt 45:2310-2324

Eleveld MA, Pasterkamp R, Van der Woerd H-J, Pietrzak JD (2008) Remotely sensed seasonality in the spatial distribution of seasurface suspended particulate matter in the southern North Sea. Estuar Coast Shelf Sci 80:103-113

Feng H, Campbell JW, Dowell MD, Moore TS (2005) Modeling spectral reflectance of optically complex waters using bio-optical measurements from Tokyo Bay. Remote Sens Environ 99:232-243

Gordon HR, Brown OB, Jacobs MM (1975) Computed relationships between the inherent and apparent optical properties of a flat homogeneous ocean. Appl Opt 14:417-427

Grossart H-P, Brinkhoff T, Martens T, Duerselen C, Liebezeit G, Simon M (2004) Tidal dynamics of dissolved and particulate matter and bacteria in a tidal flat ecosystem in spring and fall. Limnol Oceanogr 49:2212-2222 
Heuermann R, Reuter R, Willkomm R (1999) RAMSES, a modular multispectral radiometer for light measurements in the UV and VIS. SPIE proceedings series, environmental sensing and applications. In: Conference proceedings, Munich, Germany, vol. 3821. pp. 279-285

Hoge FE, Lyon PE (2005) New tools for the study of oceanic eddies: Satellite derived inherent optical properties. Remote Sens Environ 95:444-452

Hommersom A, Peters S, Wernand MR, De Boer J (2009) Spatial and temporal variability in bio-optical properties of the Wadden Sea. Estuar Coast Shelf Sci 83:360-370

Jerlov NG (1976) Marine optics. Elsevier, Amsterdam, p 231

Jianguang W, Qing X, Qinhuo L, Yi Z (2007) Extraction of chlorophyll- $a$ concentration based on spectral unmixing model using field hyperspectral data in Taihu Lake. Defence technical information Centre, OMB No. 0704-0188, p. 3, 2003. Scientia Geographica 27, $92-97$ (in Chinese)

Lemke A, Lunau M, Stone J, Dellwig O, Simon M (2009) Spatiotemporal dynamics of suspended matter properties and bacterial communities in the back-barrier tidal flat system of Spiekeroog Island. Ocean Dyn 59:277-290

Loisel H, Mériaux X, Berthon J-F, Poteau A (2007) Investigation of the optical backscattering to scattering ratio of marine particles in relation to their biogeochemical composition in the eastern English Channel and southern North Sea. Limnol Oceanogr 52:739-752

Lubac B, Loisel H (2007) Variability and classification of remote sensing reflectance spectra in the eastern English Channel and southern North Sea. Remote Sens Environ 110:45-58

Magnuson A, Harding LW Jr, Mallonee ME, Adolf JE (2004) Biooptical model for Chesapeake Bay and the Middle Atlantic Bight. Estuar Coast Shelf Sci 61:403-424

Martin Traykovski LV, Sosik HM (2003) Feature-based classification of optical water types in the Northwest Atlantic based on satellite ocean color data. J Geophys Res-Oceans 108(C5): 3150. doi:10.1029/2001JC001172

Moore TS, Campbell JW, Feng H (2001) A fuzzy logic classification scheme for selecting and blending satellite ocean color algorithms. IEEE Tranasactions Geosci Remote Sens 39:1764-1776

Moore TS, Campbell JW, Dowell MD (2009) A class-based approach to characterizing and mapping the uncertainty of the MODIS ocean chlorophyll product. Remote Sens Environ $113: 2424-2430$

Morel A, Prieur L (1977) Analysis of variations in ocean color. Limnol Oceanogr 22:709-222

Morel A, Gentili B, Claustre H, Babin M, Bricaud A, Ras J, Tièche F (2007) Optical properties of the "clearest" natural waters. Limnol Oceanogr 52:217-222

Mueller JL, Fargion GS, McClain CR (2003) Ocean optics protocols for satellite ocean color sensor validation, Revision 4, volumes I-VII. NASA Goddard Space Flight Space Center, Greenbelt, p 141

Oliver MJ, Irwin AJ (2008) Objective global ocean biogeographic provinces. Geophys Res Lett 35:L15601. doi:10.1029/ 2008GL034238
Oliver MJ, Glenn S, Kohut JT, Irwin AJ, Schofield OM (2004) Bioinformatic approaches for objective detection of water masses on continental shelves. J Geophys Res-Oceans 109: C07S04. doi:10.1029/2003JC002072

Oubelkheir K, Clementson LA, Webster IT, Ford PW, Dekker AG, Radke LC, Daniel P (2006) Using inherent optical properties to investigate biogeochemical dynamics in a tropical macrotidal coastal system. J Geophys Res Oceans 111:15

Pope RM, Fry ES (1997) Absorption spectrum (380-700 nm) of pure water. II. Integrating cavity measurements. Appl Opt 36:8710 8722

Poremba K, Tillmann U, Hesse K-J (1999) Tidal impact on planktonic primary and bacterial production in the German Wadden Sea. Helgol Mar Res 53:19-27

Postma H (editor) (1982) Hydrography of the Wadden Sea: movements and properties of water and particulate matter. Report 2 . Final report of the section Hydrography of the Wadden Sea Working Group. Leiden, the Netherlands. p. 75

Reinart A, Herlevi A, Arst H, Sipelgas L (2003) Preliminary optical classification of lakes and coastal waters in Estonia and south Finland. J Sea Res 49:357-366

Santer R, Zagolski F (2009) Algorithm Theoretical Basis Documentthe MERIS level 1c. Issue 1, rev. 1, 6 Jan 2009. p. 15

Schiller H, Schönfeld W, Krasemann HL, Schiller K (2007) Novelty detection - recognition and evaluation of exceptional water reflectance spectra. Environ Monit Assess 132:339-350

Schofield O, Bergmann T, Oliver MJ, Irwin A, Kirkpatrick G, Bissett WP, Moline MA, Orrico C (2004) Inversion of spectral absorption in the optically complex coastal waters of the MidAtlantic Bight. J Geophys Res Oceans 109. doi:10.1029/ 2003JC002071

Stanev EV, Grayek S, Staneva J (2009) Temporal and spatial circulation patterns in the East Frisian Wadden Sea. Ocean Dyn 59:167-181

Tomczak M (1999) Some historical, theoretical and applied aspects of quantitative water mass analysis. J Mar Res 57:275-303

Tyler AN, Svab E, Preston T, Présing M, Kovács WA (2005) Remote sensing of the water quality of shallow lakes: a mixture modelling approach to quantifying phytoplankton in water characterized by high-suspended sediment. Int J Remote Sens 27:1521-1537

Van der Wal D, Van Kessel T, Eleveld MA, Vanlede J (2010) Spatial heterogeneity in estuarine mud dynamics. Ocean Dyn 60:519-533

Van Der Woerd HJ, Pasterkamp R, Peters SWM, Eleveld MA (2004) How to deal with spatial variability in bio-optical properties in coastal waters: a case study of CHL-retrieval for the North Sea. In: Proceedings of the Ocean Optics conference XVII, Fremantle, Austria. p. 10

Zortea M, Plaza A (2009) Spatial preprocessing for end-member extraction. IEEE Trans Geosci Remote Sens 47:2679-2693

Zurita-Milla R (2008) Mapping and monitoring heterogeneous landscapes: spatial, spectral and temporal unmixing of MERIS data. Ph.D. thesis, Wageningen University, Wageningen, the Netherlands. p. 149 